\title{
Dissociation Channels of the 1-Propenyl Radical and Its Photolytic Precursor cis-1-Bromopropene ${ }^{\dagger}$
}

\author{
Melita L. Morton, Johanna L. Miller, and Laurie J. Butler* \\ The James Franck Institute and Department of Chemistry, The University of Chicago, Chicago, Illinois 60637
}

\author{
Fei Qi ${ }^{*}$ \\ Chemical Sciences Division, Lawrence Berkeley National Laboratory, Berkeley, California 94720
}

Received: February 1, 2002

\begin{abstract}
The primary photodissociation dynamics of cis-1-bromopropene upon excitation at $193 \mathrm{~nm}$ and the unimolecular dissociation dynamics of the nascent 1-propenyl radical are investigated in a crossed laser-molecular beam apparatus. The lowest-energy dissociation barrier of the 1-propenyl radical is experimentally determined for the first time and is found to be $31.5 \pm 2.0 \mathrm{kcal} / \mathrm{mol}$, in substantial agreement with the theoretical calculations of Davis et al. There are three dissociation channels of the 1-propenyl radical seen in these experiments: $\mathrm{C}-\mathrm{C}$ bond fission to give $\mathrm{C}_{2} \mathrm{H}_{2}+\mathrm{CH}_{3}, \mathrm{C}-\mathrm{H}$ bond fission to give propyne $+\mathrm{H}$, and isomerization to the allyl radical followed by $\mathrm{H}$ atom loss to give allene $+\mathrm{H}$. The data show that the $\mathrm{C}-\mathrm{C}$ fission channel dominates the product branching for the dissociative radicals with the lowest internal energies. The branching to the $\mathrm{H}+$ allene channel at higher energies suggests that the calculated isomerization barrier is too high with respect to the $\mathrm{H}+$ propyne barrier. The data for the precursor molecule, cis-1-bromopropene, indicate that there are at least three competing primary product channels, $\mathrm{HBr}$ elimination and two $\mathrm{C}-\mathrm{Br}$ bond fission pathways leading to 1-propenyl $+\mathrm{Br}$ formation. In addition, there is a product channel described by the total reaction $\mathrm{C}_{3} \mathrm{H}_{5} \mathrm{Br} \rightarrow \mathrm{Br}+\mathrm{H}_{2}+\mathrm{C}_{3} \mathrm{H}_{3}$. We also show evidence that the $\mathrm{Br}$ atom is formed in the excited $\left({ }^{2} \mathrm{P}_{1 / 2}\right)$ spin-orbit state from the $\mathrm{C}-\mathrm{Br}$ bond fission product channels.
\end{abstract}

\section{Introduction}

Gaining the ability to predict the course of chemical reactions is a primary objective of studies of chemical dynamics. Gasphase experiments are particularly advantageous, because the species of interest can be produced and studied without perturbation by solvent or other intermolecular interactions. Such experimental investigations go hand in hand with theoretical investigations into chemical dynamics, in which the electronic potential energy surfaces are calculated and then either classical trajectory or quantum dynamical calculations along the energy surfaces provide detailed information about product branching, energy partitioning, and reaction rates. Recently, we have begun extending our quest for predictive ability regarding the course of chemical reactions beyond the primary photodissociation reactions of closed-shell species to the unimolecular dissociation reactions of free-radical isomers. New experimental techniques allow us to resolve competing isomerization and dissociation channels of hot hydrocarbon radical isomers formed from the appropriate halogenated precursor as a function of internal energy. We are aided in this investigation by an experimental setup that disperses the nascent radicals formed from the photolysis of the halocarbons by the internal energy imparted to the radical in that primary $\mathrm{C}-\mathrm{X}$ bond-fission reaction, and then disperses the radical unimolecular dissociation products to identify how product branching changes as a function of internal energy in the radical. This key feature allows us to

\footnotetext{
† Part of the special issue "R. Stephen Berry Festschrift".

* To whom correspondence should be sent.

$\doteqdot$ Present address: Combustion Research Facility, Sandia National Laboratories, Livermore, CA 94550.
}

produce and examine the dissociation dynamics of hot, transient, and usually elusive intermediates with desired ranges of energies under collisionless conditions.

In our first set of studies in this investigation, we begin with the photodissociation of unsaturated halocarbons of the form $\mathrm{C}_{3} \mathrm{H}_{5} \mathrm{X}$. These precursors yield one of three noncyclic $\mathrm{C}_{3} \mathrm{H}_{5}$ radical isomers, which when produced with enough internal energy can mutually isomerize, dissociate, or both. We have previously presented our work ${ }^{1,2}$ on two of the three radical isomers, the 2-propenyl radical and the allyl radical; this paper presents our product translational energy spectroscopy measurements of the primary photofragment channels of cis-1-bromopropene excited at $193 \mathrm{~nm}$ and the secondary unimolecular reaction channels of the nascent 1-propenyl radical formed in the $\mathrm{C}-\mathrm{Br}$ bond fission event. This is the first study under collisionless conditions of the 1-propenyl radical unimolecular dissociation dynamics.

The $\mathrm{C}_{3} \mathrm{H}_{5}$ radical isomers, important intermediates in many chemical reactions such as those of combustion, soot formation, and others, are of much interest both experimentally and theoretically. Several investigations have probed the reactions of internally excited allyl radicals under collisionless conditions, ${ }^{2,3}$ and the unimolecular dissociation of the 2-propenyl radical was recently examined by Mueller et al. in their investigation of the $193 \mathrm{~nm}$ photodissociation of 2-chloropropene. ${ }^{1,4}$ In contrast, there are few studies that include an exploration into the isomerization and dissociation pathways of the third noncyclic $\mathrm{C}_{3} \mathrm{H}_{5}$ isomer, the 1-propenyl radical. Zhu and co-workers ${ }^{5}$ studied the $193 \mathrm{~nm}$ photodissociation of 1-bromopropene in a molecular beam. On the basis of their results, they proposed that isomerization of the 1-propenyl to 
the allyl radical occurs simultaneously with the photodissociation reaction. However, the picture presented was inconsistent with the heats of formation of the reaction species that are now known, and there have been no other experimental studies that focused on this radical under collisionless conditions before or since. A detailed kinetics study by Davis et al. ${ }^{6}$ examined the $\mathrm{C}_{3} \mathrm{H}_{5}$ system, and in the theoretical work in that paper, they calculated the critical points on the ground potential energy surface for isomerization and dissociation, as well as RiceRamsperger-Kassel-Marcus (RRKM) parameters for the three isomers. Our recent experimental work on the allyl and 2-propenyl radicals have supported these calculations, showing that a previous experimental determination ${ }^{7}$ of the allyl $\rightarrow$ 2-propenyl isomerization barrier is too low by at least $15 \mathrm{kcal} /$ mol. The goal of the present work is to cleanly produce and investigate the 1-propenyl radical with internal energies spanning the critical range for possible reaction pathways of this third $\mathrm{C}_{3} \mathrm{H}_{5}$ isomer. Our data also determines for the first time the experimental lowest-energy dissociation barrier of this elusive 1-propenyl radical.

We have found little reference to 1-bromopropene in the literature, and other than the previously mentioned molecular beam study by Zhu et al., we did not find any information about the absorption spectrum or likely excited states of this molecule. Because the bromine is attached to a vinylic carbon, we looked to the literature on vinyl bromide for information on absorption bands and potential energy surfaces for the unsaturated $\mathrm{C}-\mathrm{Br}$ bond fission system. Vinyl bromide has been fairly well studied, both theoretically and experimentally. ${ }^{8-11}$ The A band of the absorption spectrum of vinyl bromide has a strong $(\sigma=1.5 \times$ $10^{-17} \mathrm{~cm}^{2} /$ molecule) maximum at $52200 \mathrm{~cm}^{-1}$ that is assigned to a $\pi^{*} \leftarrow \pi$ transition, ${ }^{12}$ although we would expect the bromine atom to participate in the excitation as well. For comparison, the absorption wavelength of 2-chloropropene, another molecule for which a hydrogen atom is replaced with a methyl group, did not significantly change from that seen for vinyl chloride, so we expect that using $193 \mathrm{~nm}$ will access a similar transition in 1-bromopropene as that seen in vinyl bromide. The first four potential energy surfaces in $C_{S}$ symmetry for $\mathrm{C}-\mathrm{Br}$ bond fission in vinyl bromide have been modeled ${ }^{13}$ in both the singlet and triplet manifolds (without spin-orbit coupling), and when we analyze our results in the discussion section of this paper, we will refer to this calculation. Using recent theoretical calculations ${ }^{6,14}$ to find the heat of formation of cis-1-propenyl radical along with other thermochemical data ${ }^{15}$ to estimate a $D_{0}$ for the $\mathrm{C}-\mathrm{Br}$ bond fission in cis-1-bromopropene yielded a value of $80.9 \mathrm{kcal} / \mathrm{mol}$, which we adopted for analyzing these experiments. (The value given is calculated for a reaction temperature of $298 \mathrm{~K}$ because the data to determine the enthalpy of formation of cis-1-bromopropene at $0 \mathrm{~K}$ is not available. See Discussion for a clarification of the values used and error bars.) After cleavage of the $\mathrm{C}-\mathrm{Br}$ bond, the nascent 1-propenyl formed can then isomerize, dissociate, or both; as noted above the relevant energies and barrier heights of the $\mathrm{C}_{3} \mathrm{H}_{5}$ system were calculated by Davis et al. We also looked for other possible photoinduced reactions such as $\mathrm{HBr}$ elimination. Figure 1 details the energetics for the primary and secondary reactions of cis1-bromopropene excited at $193 \mathrm{~nm}$ that will be discussed in this paper.

\section{Experimental Section}

These experiments measure the recoil velocity distributions of fragments from the photodissociation of cis-1-bromopropene excited at $193.3 \mathrm{~nm}$. We also measure the arrival times of the

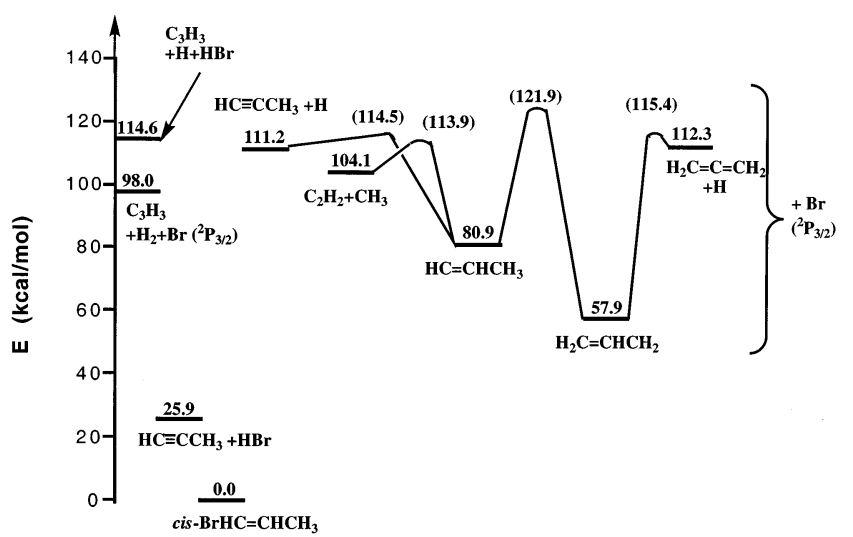

Figure 1. Energy diagram for several of the important primary and secondary product channels in the photodissociation of cis-1-bromopropene at $193 \mathrm{~nm}$. The energetics and barrier heights for isomerization or bond fission of the $\mathrm{C}_{3} \mathrm{H}_{5}$ radical system are taken from the work of Davis et al., ${ }^{6}$ and the energetics for $\mathrm{C}-\mathrm{Br}$ bond fission, $\mathrm{HBr}$ elimination, and $\mathrm{H}_{2}$ elimination are estimated from the values of heats of formation of the reaction species taken from NIST Chemistry Webbook. ${ }^{15}$ Energetics are calculated using the following literature $\Delta H_{\mathrm{f}, 298 \mathrm{~K}}$ values without conversion to $\Delta \mathrm{H}_{\mathrm{f}, 0 \mathrm{~K}}$ because the conversions were unavailable for several species: $\Delta H_{\mathrm{f}}\left(\mathrm{C}_{3} \mathrm{H}_{5} \mathrm{Br}\right)=9.7 \mathrm{kcal} / \mathrm{mol} ; \Delta H_{\mathrm{f}}(\mathrm{Br})=26.74$ $\mathrm{kcal} / \mathrm{mol} ; \Delta H_{\mathrm{f}}($ allyl $)=40.9 \mathrm{kcal} / \mathrm{mol} ; \Delta H_{\mathrm{f}}(\mathrm{HBr})=-8.67 \mathrm{kcal} / \mathrm{mol}$; $\Delta H_{\mathrm{f}}\left(\mathrm{C}_{3} \mathrm{H}_{3}\right)=81.0 \mathrm{kcal} / \mathrm{mol}$.

secondary products from the dissociation of the vibrationally hot photoproducts. We carried out the experiments using the rotating-source, fixed-detector molecular beam apparatus on the Chemical Dynamics Beamline at Lawrence Berkeley National Laboratory's Advanced Light Source (ALS). This apparatus is a crossed laser-molecular beam apparatus with the key feature of using tunable VUV photons from the ALS to ionize the neutral photofragments in the detector, rather than the more traditional electron-bombardment method. Dispersing the radicals produced in the primary photolysis step along with the momentum-matched halogen atoms and the heavy product from the $\mathrm{C}-\mathrm{H}$ bond fission of each unstable radical gives a unique advantage. It allows us to identify for each dissociation product the internal energy of the nascent unstable radical that decomposed to give that radical decomposition product. This ability results from the fact that products produced by $\mathrm{H}$ atom loss from the initial photoproducts travel with essentially the same velocity as their nascent parents. Therefore, because the arrival time of the secondary product identifies the translational energy of the radical from which it came, conservation of energy allows us to deduce the internal energy of the dissociating species. The use of the "soft" photoionization also largely prevents primary photofragments or radical unimolecular dissociation products from cracking in the ionization process, allowing easier identification of the neutral products formed in the primary and secondary (radical) dissociations. Specific details of the apparatus at the ALS have been described elsewhere. ${ }^{16}$

The 9\% cis-1-bromopropene/helium-pulsed molecular beam was generated by bubbling helium through a sample of liquid cis-1-bromopropene cooled to $0{ }^{\circ} \mathrm{C}$ to give a total backing pressure of 760 Torr. The gas mixture was expanded through a lightly heated $\left(50{ }^{\circ} \mathrm{C}\right)$ piezo valve with a nozzle diameter size of $1 \mathrm{~mm}$, operating at $100 \mathrm{~Hz}$. There was no evidence of clusters at the conditions used in these experiments. The parent beam velocity was measured by directing the molecular beam straight into the detector and either analyzing the shape of the "hole" formed in the signal by the laser at $m / e=41$ or raising a chopper wheel into the beam and measuring the time of arrival of 1-bromopropene molecules at an appropriate daughter ion as a 
function of distance from the chopper wheel. Representative beam velocities varied, with a typical peak molecular beam velocity in the number density distribution, $N(v)$, for the beam time-of-flight measurements of $(13.2-14.0) \times 10^{4} \mathrm{~cm} / \mathrm{s}$ with a velocity spread $\left(\Delta v / v_{\text {peak }}\right)$ of $16 \%$ with $\Delta v$ calculated from the full width at half-maximum of $N(v)$.

The laser used in this work is a Lambda Physik LPX-200 excimer laser operating on the $193.3 \mathrm{~nm}$ ArF transition at a pulse energy of 4-6 mJ/pulse. Because the absorption cross section of 1-bromopropene at $193 \mathrm{~nm}$ is unavailable, we performed multiple power dependence studies in which the intensity of the signal at various photofragments was measured as a function of laser power. At the chosen range of pulse energies, signal intensity increased linearly with laser power, indicating that only one-photon processes contributed significantly. The laser beam, focused to a $2 \mathrm{~mm} \times 4 \mathrm{~mm}$ spot, intersects the molecular beam at an angle of $90^{\circ}$ to the plane defined by the molecular beam and detector axis. Molecules absorb light and dissociate, imparting recoil kinetic energy to the photofragments, and a small fraction of the products scatter into the detector, traveling $15.2 \mathrm{~cm}$ to the point where they are ionized by tunable VUV radiation from the ALS. The characteristics of the light source have been described in detail elsewhere. ${ }^{16}$ The photofragment time-of-flight spectra presented in this paper were taken with a light source bandwidth of $4.5 \%$ and the photoionization efficiency spectra and the $m / e=40$ data at 10.0 and $10.8 \mathrm{eV}$ with a $2.2 \%$ bandwidth. A gas filter filled with 25 Torr Ar eliminates unwanted higher harmonics

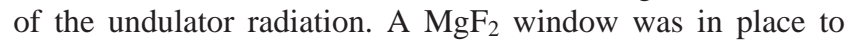
filter out any remaining high-energy photons when the probe energy was at or below $10.8 \mathrm{eV}$.

Ions of the mass of interest are mass-selected using a quadrupole mass filter and counted as a function of total flight time from the interaction region using a Daly detector. The ion flight time constant of $\alpha=5.42 \mu \mathrm{s} / \mathrm{amu}^{1 / 2}(\mathrm{~m} / \mathrm{e}=41$ data and photoionization efficiency curve data for $m / e=40$ ), $\alpha=6.14$ $\mu \mathrm{s} / \mathrm{amu}^{1 / 2}$ (low-mass quadrupole, all other masses below $m / e$ $=41$ ), or $\alpha=6.85 \mu \mathrm{s} / \mathrm{amu}^{1 / 2}$ (high-mass quadrupole, all masses above $m / e=41)$ was used to correct for the flight time $\left(\alpha \sqrt{ } m_{\text {ion }}\right)$ of ions through the mass spectrometer; note that figures show total (neutral + ion) flight times.

\section{Results and Analysis}

The data for cis-1-bromopropene excited at $193 \mathrm{~nm}$ indicate that there are at least three competing primary product channels, $\mathrm{HBr}$ elimination and two $\mathrm{C}-\mathrm{Br}$ bond fission pathways leading to 1-propenyl $+\mathrm{Br}$ formation. One of the $\mathrm{C}-\mathrm{Br}$ bond fission pathways is a channel in which a large amount of translational energy is imparted to the recoiling photofragments (a "fast" channel), and the other is a channel in which the photofragments produced have higher internal energy and less translational energy (the "slow" C-Br bond fission channel). After the initial photodissociation event, the nascent 1-propenyl radicals formed from $\mathrm{C}-\mathrm{Br}$ bond fission can and do undergo secondary dissociation when produced with enough internal energy, either by $\mathrm{C}-\mathrm{C}$ bond fission or by $\mathrm{H}$-atom loss (potentially via isomerization). Likewise, the $\mathrm{C}_{3} \mathrm{H}_{4}$ cofragment in the $\mathrm{HBr}$ elimination primary reaction also undergoes secondary decomposition to give $\mathrm{C}_{3} \mathrm{H}_{3}+\mathrm{H}$ as final products. In addition, there is a product channel described by the total reaction $\mathrm{C}_{3} \mathrm{H}_{5} \mathrm{Br} \rightarrow$ $\mathrm{Br}+\mathrm{H}_{2}+\mathrm{C}_{3} \mathrm{H}_{3}$; we cannot definitively determine whether $\mathrm{H}_{2}$ elimination occurs from the $\mathrm{C}_{3} \mathrm{H}_{5} \mathrm{Br}$ molecule (followed by swift $\mathrm{C}-\mathrm{Br}$ bond fission) or from hot mass 41 radicals formed after the $\mathrm{C}-\mathrm{Br}$ bond breaks in the parent molecule. $\mathrm{C}-\mathrm{C}$ bond fission

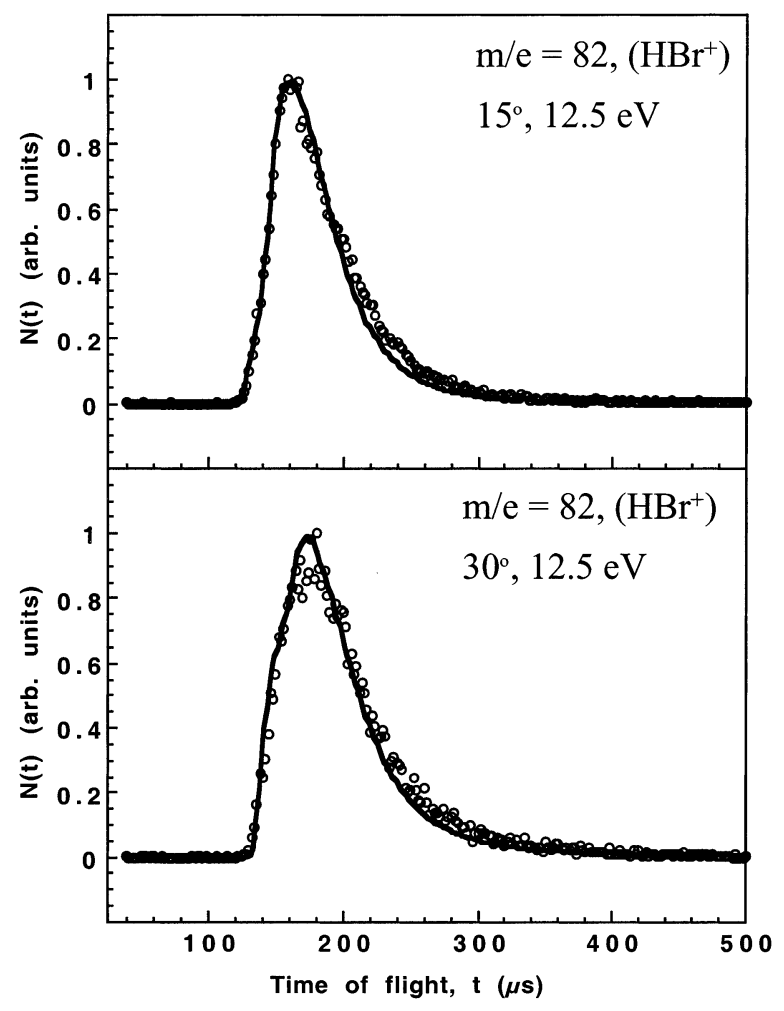

Figure 2. Time-of-flight spectra of $m / e=82\left(\mathrm{H}^{81} \mathrm{Br}^{+}\right)$photoionized at $12.5 \mathrm{eV}$ at source-detector angles of $15^{\circ}$ and $30^{\circ}$. The data, shown in open circles, is fit by using the $\mathrm{HBr}$ elimination $P\left(E_{\mathrm{T}}\right)$ shown in Figure 3.

of cis-1-bromopropene was looked for but not seen, and $\mathrm{C}-\mathrm{H}$ bond fission would produce fragments too heavy to recoil out to the detection angles sampled. We also show evidence that the $\mathrm{Br}$ atom is formed in the excited $\left({ }^{2} \mathrm{P}_{1 / 2}\right)$ spin-orbit state from the $\mathrm{C}-\mathrm{Br}$ bond fission product channels.

$\mathrm{HBr}$ Elimination from cis-1-Bromopropene at $193 \mathrm{~nm}$ and Secondary Decomposition of the Nascent $\mathrm{C}_{3} \mathrm{H}_{4}$ Cofragment. In Figure 2, we show the time-of-flight (TOF) spectra of $\mathrm{HBr}$, $m / e=82\left(\mathrm{H}^{81} \mathrm{Br}^{+}\right)$, collected for 15000 laser shots using a photoionization energy of $12.5 \mathrm{eV}$. The signal comprises a single, broad peak from 120 to $300 \mu$ s and is fit by the forward convolution method with the $P\left(E_{\mathrm{T}}\right)$ shown in Figure 3. This $P\left(E_{\mathrm{T}}\right)$ is the translational energy distribution for the $\mathrm{HBr}$ and its momentum-matched cofragment in the center-of-mass reference frame. It extends to near $38 \mathrm{kcal} / \mathrm{mol}$ from a maximum near $0 \mathrm{kcal} / \mathrm{mol}$; peaking near zero indicates that the exit channel dynamics in the $\mathrm{HBr}$ elimination process preferentially partitions energy into internal energy of the products rather than into recoil translational energy.

The cofragment to $\mathrm{HBr}$ elimination from cis-1-bromopropene is a mass 40 product, $\mathrm{C}_{3} \mathrm{H}_{4}$ (allene, propyne, an unstable cyclic intermediate, or a biradical are all energetically allowed). However, the reaction $\mathrm{C}_{3} \mathrm{H}_{5} \mathrm{Br} \rightarrow \mathrm{HBr}+\mathrm{C}_{3} \mathrm{H}_{4}$ in which the cofragment is propyne (or allene) requires only 25.9 (27.1) kcal/ mol (calculated using heats of formation at $298 \mathrm{~K})^{15}$ leaving $\sim 122 \mathrm{kcal} / \mathrm{mol}(147.9-25.9 \mathrm{kcal} / \mathrm{mol})$ available for internal energy of the two reaction products. Loss of $\mathrm{H}$ atom from propyne requires $88.7 \mathrm{kcal} / \mathrm{mol}$ (from allene the value is lower by $0.9 \mathrm{kcal} / \mathrm{mol}$ ). Thus, the nascent $\mathrm{C}_{3} \mathrm{H}_{4}$ formed has enough internal energy to undergo secondary $\mathrm{H}$ atom loss over very nearly the whole range of translational energies produced, within the $2-3 \mathrm{kcal} / \mathrm{mol}$ error bars inherent in forward convolution fitting and allowing for a small amount of internal energy of 


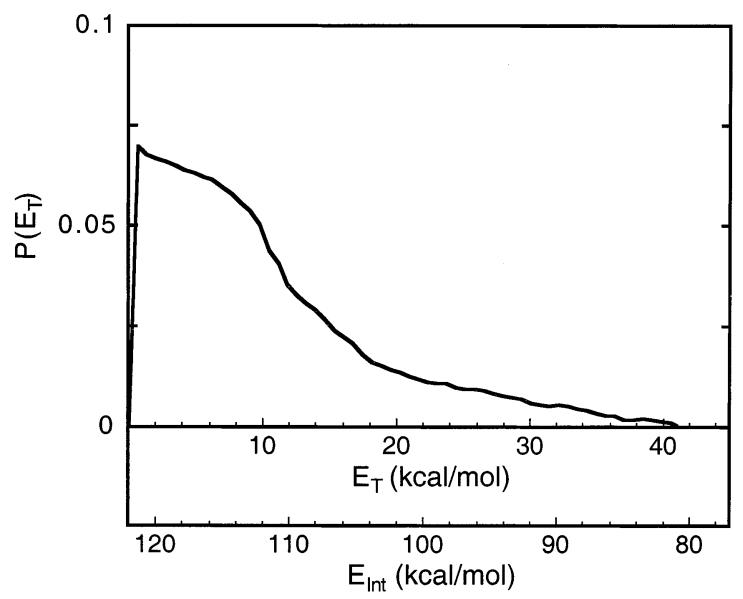

Figure 3. Product translational energy distribution, $P\left(E_{\mathrm{T}}\right)$, for $\mathrm{HBr}$ elimination in the $193 \mathrm{~nm}$ photolysis of cis-1-bromopropene derived from forward convolution fitting of the signal in Figure 2. The top $x$-axis shows the translational energy, and the bottom axis shows the internal energy partitioned to the photoproducts with each kinetic energy release for $\mathrm{HBr}$ elimination calculated from $E_{\text {int,fragments }}=h v-\Delta H-$ $E_{\mathrm{T}}=147.9-25.9 \mathrm{kcal} / \mathrm{mol}-E_{\mathrm{T} \text {.fragments }}$ (with the $\Delta H$ estimated from $298 \mathrm{~K}$ heats of formation of all species because the $0 \mathrm{~K}$ heat of formation was unavailable for the precursor).

the parent molecule $(2 \mathrm{kcal} / \mathrm{mol})$. If instead the nascent mass 40 product remains stable to secondary dissociation and is detected at $m / e=40$, it should be significantly vibrationally excited. Figure 4 shows the TOF spectra taken at $m / e=40$ $\left(\mathrm{C}_{3} \mathrm{H}_{4}{ }^{+}\right)$collected at a source-detector angle of $15^{\circ}$ for 100000 laser shots using photoionization energies of 10.0 and $10.8 \mathrm{eV}$. There are two peaks evident. Should the signal at this mass contain a significant contribution from the $\mathrm{HBr}$ elimination cofragment $\mathrm{C}_{3} \mathrm{H}_{4}$, it would primarily be buried in the slow peak visible at this mass-to-charge ratio. Fits to these spectra will be explained in detail in the section on the $\mathrm{C}-\mathrm{Br}$ bond fission reactions of cis-1-bromopropene, but we point out now that integrating the data over the time window $100-180 \mu \mathrm{s}$ as a function of ionization energy provided us with a photoionization efficiency curve (PIE curve), which shows the contribution to these spectra from the $\mathrm{C}_{3} \mathrm{H}_{4}$ product in the $\mathrm{HBr}$ elimination reaction of cis-1-bromopropene is small; most of the $\mathrm{C}_{3} \mathrm{H}_{4}$ from $\mathrm{HBr}$ elimination is formed with enough internal energy to dissociation to $\mathrm{C}_{3} \mathrm{H}_{3}+\mathrm{H}$. This is easily seen upon considering the PIE curve for the signal arriving in this time window, which is shown in Figure 5a and includes PIE curves of pure allene and pure propyne taken by Mueller et al. ${ }^{1}$ under similar conditions on the same apparatus. PIE curves have been useful in other work to discriminate between isomers with different ionization onsets; here, we use the data to determine the extent of vibrational excitation of the mass-selected product. One can see immediately that the contribution to this curve from hot allene formed in the $\mathrm{HBr}$ elimination pathway, if any, must be extremely small: the ionization onset and curvature resemble that of the pure allene, and the curve is not red-shifted. (In contrast, $\mathrm{C}_{3} \mathrm{H}_{4}$ produced from $\mathrm{HCl}$ elimination in allyl chloride, some of which is formed with low enough internal energy to be stable to dissociation to propargyl $+\mathrm{H}$, shows a dramatically red-shifted PIE curve with an onset just below $8.5 \mathrm{eV} .^{2}$ ) Thus, most of the nascent $\mathrm{C}_{3} \mathrm{H}_{4}$ produced in the $\mathrm{HBr}$ elimination channel undergoes secondary dissociation to propargyl $+\mathrm{H}$. However, some of the $\mathrm{C}_{3} \mathrm{H}_{4}$ produced in the small higher kinetic energy tail of the $\mathrm{HBr}$ elimination $P\left(E_{\mathrm{T}}\right)$ might survive secondary dissociation. Although the data in Figure 4 is not fit with any contribution from this $\mathrm{HBr}$ elimination channel, a small

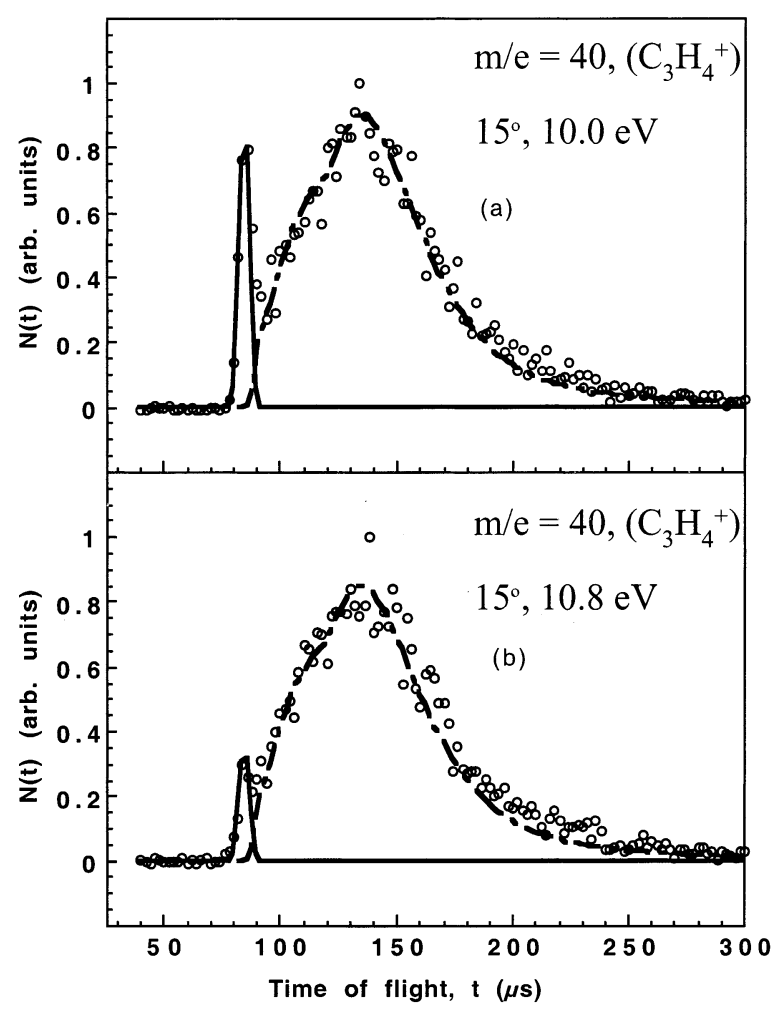

Figure 4. Time-of-flight spectra of $m / e=40\left(\mathrm{C}_{3} \mathrm{H}_{4}{ }^{+}\right)$taken for 100000 laser shots at a source-detector angle of $15^{\circ}$. Data are shown in open circles. The top spectrum shows data taken at $10.0 \mathrm{eV}$, below the 10.36 $\mathrm{eV}$ literature ionization onset of propyne but above the $9.69 \mathrm{eV}$ ionization onset of allene. The bottom spectrum was taken with a photoionization energy of $10.8 \mathrm{eV}$. The fast peak is primarily daughter ion cracking from stable mass 41 radicals produced by $\mathrm{C}-\mathrm{Br}$ bond fission that imparts a large amount of translational energy into product recoil. The slow peak is fit with only the RRKM-like dot-dashed slow $\mathrm{C}-\mathrm{Br}$ bond fission $P\left(E_{\mathrm{T}}\right)$ shown in Figure 8 that peaks at zero and extends to $24 \mathrm{kcal} / \mathrm{mol}$. Note that a small amount of mass 40 product resulting from $\mathrm{HBr}$ elimination could be included without significantly altering the fit, but as explained in the text, any $\mathrm{C}_{3} \mathrm{H}_{4}$ formed in the $\mathrm{HBr}$ elimination channel would be expected to be significantly vibrationally excited. The PIE curve shown in Figure 5 does not indicate that such a species is a significant product. A small amount of signal resulting from $\mathrm{C}-\mathrm{H}$ fission of the fast, unstable 1-propenyl radicals formed in the high kinetic energy $\mathrm{C}-\mathrm{Br}$ bond fission pathway (Figures 8 and 9) could also be included within the signal-to-noise, but including a significant fraction near-threshold dramatically overfits this spectrum. Thus, it is clear that the $\mathrm{C}-\mathrm{C}$ bond fission channel of the nascent 1-propenyl radical turns on first (consistent with the barrier height prediction of Davis et al.) and is the dominant secondary decomposition channel for these fast radicals. Because the two $m / e=40$ spectra at 10.0 and $10.8 \mathrm{eV}$ photoionization energy are identical except for the relative heights of the peak resulting from daughter ion cracking of fast stable 1-propenyl radicals, the branching ratio between $\mathrm{C}-\mathrm{H}$ bond fission from the 1-propenyl radical to form propyne and isomerization to the allyl radical (followed by $\mathrm{H}$ atom loss to give allene) must only be weakly dependent on the internal energy of the radical. (The similarity of the 10.0 and $10.8 \mathrm{eV}$ spectra is also consistent with the products being dominated by allene, but the PIE curve in Figure 5 indicates that significant branching to propyne $+\mathrm{H}$ occurs.)

amount, particularly of the fragments with higher translational energies, could be included without significantly altering the fit. Also, we note that if a larger fraction of the $\mathrm{C}_{3} \mathrm{H}_{4}$ remains stable to secondary decomposition, the $\mathrm{C}-\mathrm{Br}$ bond fission fits used for this mass could be altered (at the same time increasing the $\mathrm{C}-\mathrm{Br}$ bond fission products that show at $m / e=39$ ) so that more contribution from this $\mathrm{HBr}$ channel could be included at this mass without significantly affecting the conclusions in the rest of this paper. 

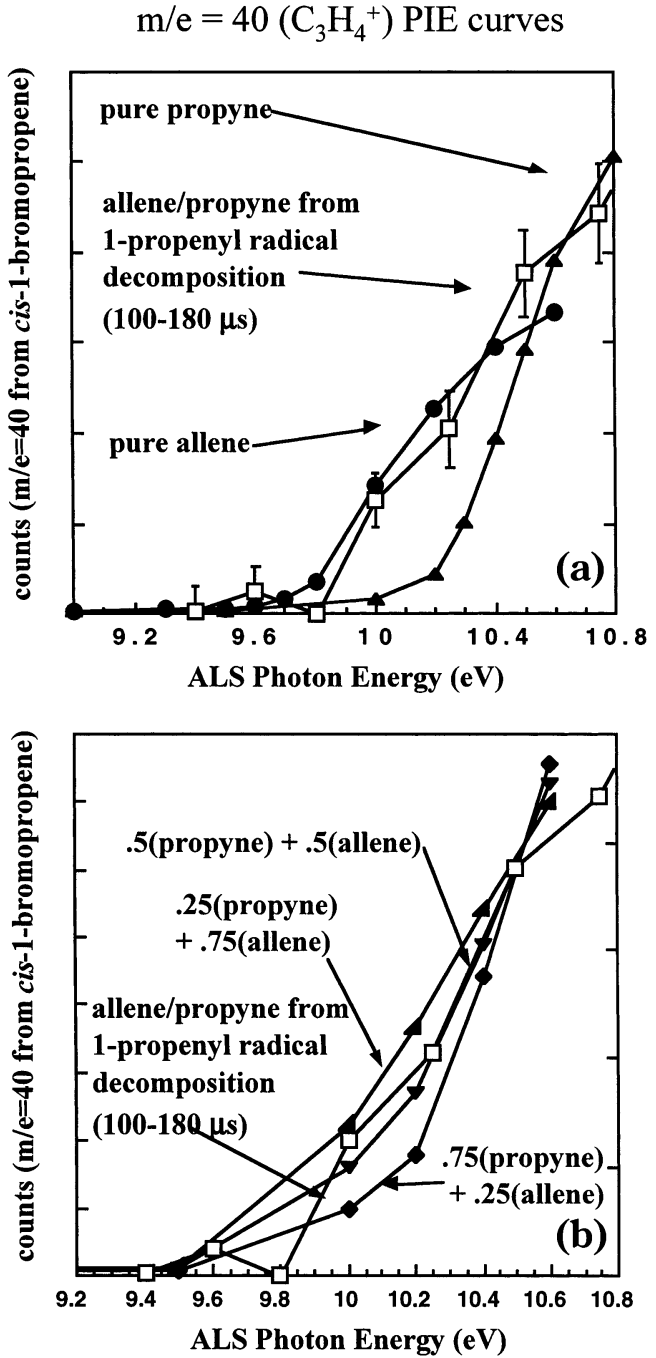

Figure 5. Photoionization efficiency (PIE) curve ( $\square$ ) for mass 40 products (a) from cis-1-bromopropene detected at source-detector angle of $15^{\circ}$ with 50000 laser shots taken at each ionization energy step. Data points are shown with error bars and with straight-line extrapolations to guide the eye. PIE curves of neat allene and neat propyne ( and $\boldsymbol{\Delta}$, respectively) taken under similar conditions are provided for comparison, reproduced with permission from the work of Mueller et al. ${ }^{1}$ Data are corrected for VUV energy. The 1-bromopropene data was normalized to bring it on scale with the data of Mueller et al. The onset of the photoionization curve of the mass 40 product resembles closely that of the cold allene and thus cannot contain a significant amount of vibrationally excited allene. Panel b shows a comparison of data $(\square)$ with three curves, each a linear combination in which we have weighted the contribution of both allene and propyne. The curve composed of $50 \%$ allene and $50 \%$ propyne $(\boldsymbol{\nabla})$ fits the data much better than the pure allene or pure propyne curves. This ratio between allene and propyne products is not well-determined, however; using a 3:1 or a $1: 3$ ratio also adequately fits the data.

We show in Figure 6 the TOF spectrum taken at $m / e=39$ $\left(\mathrm{C}_{3} \mathrm{H}_{3}{ }^{+}\right)$, collected at a source-detector angle of $15^{\circ}$ for 10000 laser shots at an ionization energy of $10.8 \mathrm{eV}$ and fit with the total $\mathrm{HBr}$ elimination $P\left(E_{\mathrm{T}}\right)$ as well as contributions from other processes (which will be discussed in the next section). The whole $\operatorname{HBr} P\left(E_{\mathrm{T}}\right)$ is required to fit the data at this mass, indicating that the nascent mass 40 products from the $\mathrm{HBr}$ elimination from cis-1-bromopropene over the entire range of translational energies produced all undergo secondary dissociation to mass $39+\mathrm{H}$. The mass 39 product is likely propargyl radical; the PIE curve taken at $m / e=39$ over a time window corresponding to the slow peak shows an ionization onset at

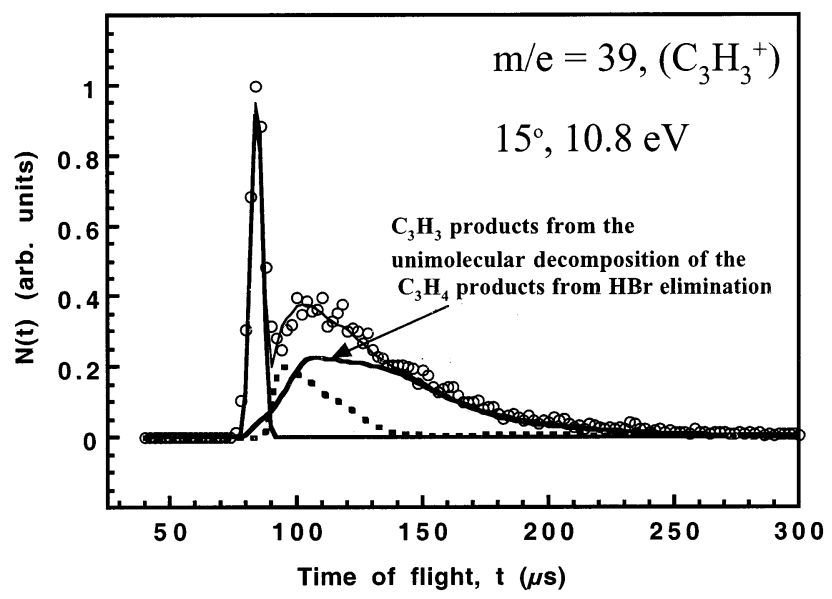

Figure 6. Time-of-flight spectra of $m / e=39\left(\mathrm{C}_{3} \mathrm{H}_{4}{ }^{+}\right)$taken for 10000 laser shots at a source-detector angle of $15^{\circ}$. Data are shown in open circles, and overall fit is in thin solid line. The fast peak is fit as daughter ion cracking of the stable mass 41 radicals (solid line portion of the fast $P\left(E_{\mathrm{T}}\right)$ shown in Figure 8$)$. This assignment is confirmed by the increase in the relative intensity of this fast peak as ionization energy is increased. The slow peak is fit as the sum of contributions from two channels, $\mathrm{HBr}$ elimination that produces unstable mass 40 products that undergo $\mathrm{C}-\mathrm{H}$ bond fission to give propargyl radicals (thick solid line) and $\mathrm{C}_{3} \mathrm{H}_{3}$ products from the reaction $\mathrm{BrHC}=\mathrm{CHCH}_{3} \rightarrow \mathrm{C}_{3} \mathrm{H}_{3}+$ $\mathrm{Br}+\mathrm{H}_{2}$ (dotted line)

$\sim 8.6 \mathrm{eV}$, near the $8.67 \mathrm{eV}$ literature ionization onset of propargyl radical. This PIE curve also resembles closely the curves seen for the mass 39 secondary products produced from the primary photodissociation reaction products of allyl chloride and 2-chloropropene, in which both were assigned as production of propargyl $+\mathrm{H}^{1,2}$

$\mathrm{C}-\mathrm{Br}$ Bond Fission Reactions of cis-1-Bromopropene at $193 \mathrm{~nm}$ and Secondary Decomposition of the Nascent 1-Propenyl Radical. In Figure 7, we show the time-of-flight (TOF) spectra of $\mathrm{Br}$ atoms, $m / e=79\left(\mathrm{Br}^{+}\right)$, collected for 30000 laser shots using photoionization energies of 11.5 and $15.5 \mathrm{eV}$. Two peaks are clearly evident, one a narrow peak centered at approximately $140 \mu \mathrm{s}$ and the other a broad slow distribution extending from $\sim 150$ to $\sim 250 \mu \mathrm{s}$. In Figure 8 , we show the photofragment recoil translational energy distributions, the $P\left(E_{\mathrm{T}}\right)$ 's, obtained by forward convolution fitting of the $m / e=$ 79 TOF spectra. Note that the higher translational energy $P\left(E_{\mathrm{T}}\right)$ (shown in overall thick solid line) is further broken down into two different components (thin solid line and dashed line). We show the two components rather than combining them into one because the thin solid line part of the fast $P\left(E_{\mathrm{T}}\right)$ describes the portion of the $\mathrm{C}-\mathrm{Br}$ fission reactions that releases the largest amount of energy into product recoil, leaving the nascent momentum-matched mass 41 photofragments, the 1-propenyl radicals, with low enough internal energy that they remain stable and are detected at $m / e=41$. The TOF spectra of $m / e=41$ $\left(\mathrm{C}_{3} \mathrm{H}_{5}{ }^{+}\right)$shown in Figure 9 are thus fit only with this (thin solid line) portion of the fast $P\left(E_{\mathrm{T}}\right)$ used to fit the $m / e=79$ data. The energy available for translational and internal energy of $\mathrm{C}-\mathrm{Br}$ bond fission products of 1-bromopropene at $193 \mathrm{~nm}$ is $67.0 \mathrm{kcal} / \mathrm{mol}$ (using enthalpies at $298 \mathrm{~K}$ and assuming no internal energy of the parent molecule). Because the lowest observed total recoil translational energy $\mathrm{C}-\mathrm{Br}$ fission that produced stable 1-propenyl radicals is $\sim 25 \mathrm{kcal} / \mathrm{mol}$, these radicals could then have internal energies as high as $42 \mathrm{kcal} /$ mol (we assign error bars of $\pm 2 \mathrm{kcal} / \mathrm{mol}$, which include accounting for possible forward convolution fitting errors as well as errors in the heats of formation used to calculate $\Delta H_{\mathrm{R}}$ ) if they are produced with a $\mathrm{Br}\left({ }^{2} \mathrm{P}_{3 / 2}\right)$ cofragment. At first this 


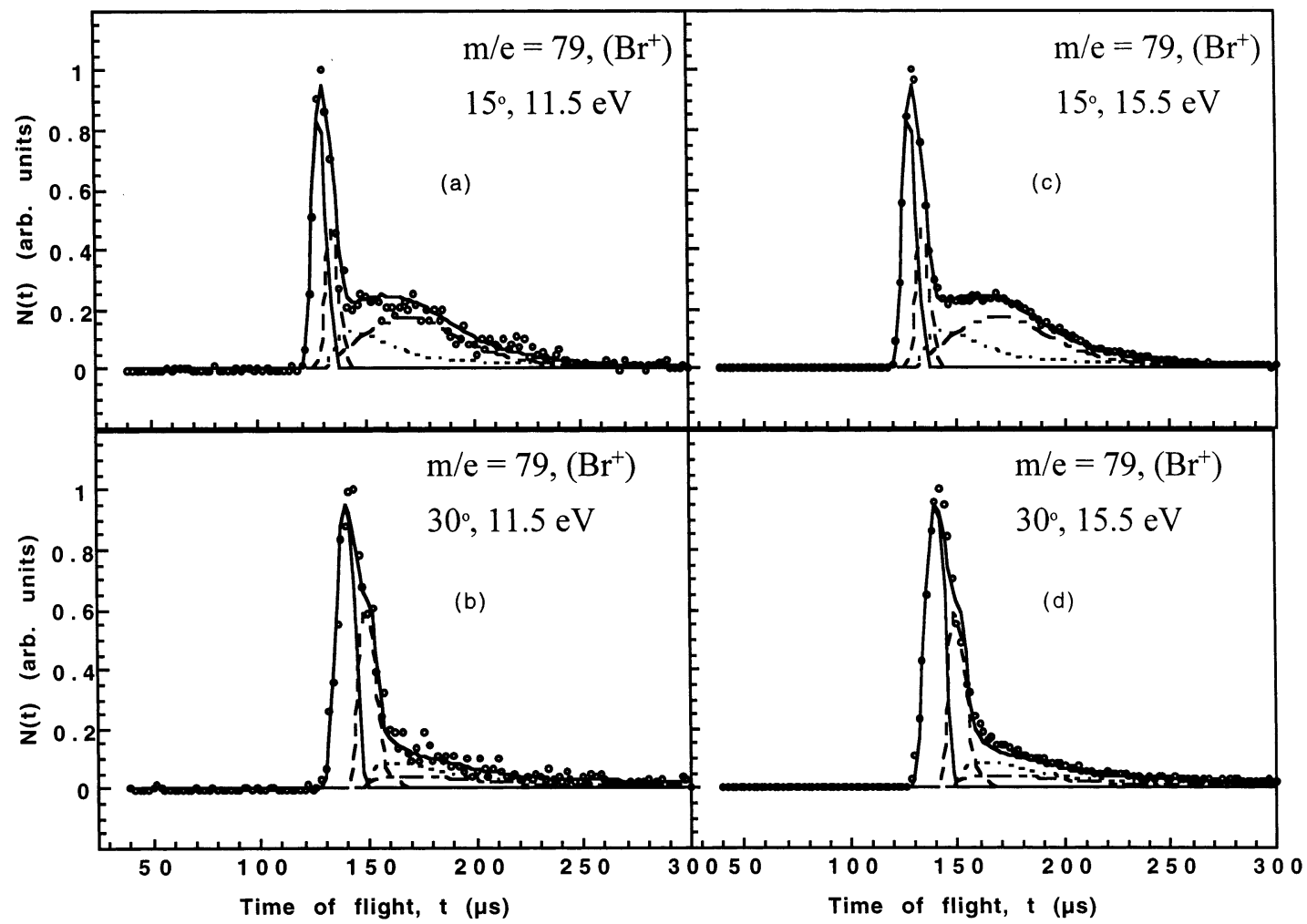

Figure 7. Time-of-flight spectra of $\mathrm{Br}$ atoms, $m / e=79\left(\mathrm{Br}^{+}\right)$, collected at source-detector angles of $15^{\circ}$ and $30^{\circ}$ for 30000 laser shots using photoionization energies of both 11.5 and $15.5 \mathrm{eV}$. The fast narrow peak centered at approximately $140 \mu \mathrm{s}$ is fit with both parts of the fast $P\left(E_{\mathrm{T}}\right)$ shown in Figure 8. This fast $P\left(E_{\mathrm{T}}\right)$ has been decomposed into two portions, the $\mathrm{Br}$ atoms that are momentum-matched to stable 1-propenyl radicals and $\mathrm{Br}$ atoms that are momentum-matched to near-threshold, unstable 1-propenyl radicals. The broad slow distribution extending from $\sim 150$ to $\sim 250 \mu \mathrm{s}$ is fit with the two slow $P\left(E_{\mathrm{T}}\right)$ 's shown in Figure 8. The relative probabilites used to weight the four contributions to this spectrum, [channel giving fast stable mass 41 cofragments]/[channel giving fast unstable mass 41 cofragments]/[low kinetic energy channel with unstable radicals producing mass 40 cofragments]/[low kinetic energy $\mathrm{H}_{2}+\mathrm{Br}+\mathrm{C}_{2} \mathrm{H}_{3}$ channel], were 0.5:0.2:0.1:0.13.

might seem to be contradictory to the data presented by Davis et al. (see Figure 1): 1-propenyl radicals look to be surviving with internal energies well over the dissociation barrier of 33.0 $\mathrm{kcal} / \mathrm{mol}$ to produce acetylene and methyl! However, if the $\mathrm{Br}$ atom is formed in its spin-orbit excited state, $\mathrm{Br}\left({ }^{2} \mathrm{P}_{1 / 2}\right), 10.5$ $\mathrm{kcal} / \mathrm{mol}$ of the available energy from the dissociation reaction is partitioned to internal energy of the $\mathrm{Br}$ atom. Subtracting 10.5 $\mathrm{kcal} / \mathrm{mol}$ from the energy maximum then puts the truncation point for the solid line part of the $P\left(E_{\mathrm{T}}\right)$ that describes the stable 1-propenyl radicals at almost exactly the barrier height for $\mathrm{C}-\mathrm{C}$ fission calculated by Davis et al. Any radicals formed in the fast channel with translational energy less than $\sim 25 \mathrm{kcal} / \mathrm{mol}$ thus have enough internal energy to undergo secondary dissociation and so do not give signal at $m / e=41$. The possible secondary dissociation reactions of these $\mathrm{C}_{3} \mathrm{H}_{5}$ radicals will be presented and discussed shortly.

To see whether we are indeed forming bromine in its first excited spin-orbit state, we tuned the photoionization energy to take spectra at $11.5 \mathrm{eV}$, below the ionization onset for groundstate $\mathrm{Br}$ atoms $(11.8 \mathrm{eV}),{ }^{15}$ and at $15.5 \mathrm{eV}$. This second ionization energy is above the $15.2 \mathrm{eV}^{1} \mathrm{~S}_{0}$ ionization threshold state of $\mathrm{Br}^{+}$, potentially eliminating any problems ${ }^{17}$ arising from the possibility that ground- and excited-state $\mathrm{Br}$ atoms have different ionization cross sections. For example, I and I* were seen to have different ionization cross sections when ionized with near-threshold radiation in the study on the photodissociation of allyl iodide by Szpunar et al. ${ }^{18}$ Because the $11.5 \mathrm{eV}$ spectra and the $15.5 \mathrm{eV}$ spectra are the same within signal-tonoise, not shifted to slower arrival times when only $\mathrm{Br}\left({ }^{2} \mathrm{P}_{1 / 2}\right)$ is detected, we conclude that $\mathrm{C}-\mathrm{Br}$ fission forms primarily bromine in its excited spin-orbit state, an unexpected result.
Then, accounting for this $10.5 \mathrm{kcal} / \mathrm{mol}$ of internal energy in the $\operatorname{Br}\left({ }^{2} \mathrm{P}_{1 / 2}\right)$ atom shows that the higher internal energy 1-propenyl radicals that are stable to unimolecular dissociation have an internal energy of $31.5 \pm 2 \mathrm{kcal} / \mathrm{mol}$, in excellent agreement with the lowest-energy barrier of the 1-propenyl radical calculated by Davis et al. Note that while the slowest signal in the $15.5 \mathrm{eV}$ spectra is slightly underfit, it is not a consistent problem that can be solved by postulating the formation of $\mathrm{Br}$ in both ground and excited states. There are two possible sources for this unfit signal seen in the spectra taken with the higher ionization energy: either a small amount of clusters or a small amount of daughter ions from mass 80 $(\mathrm{HBr})$ crack to give signal at these slow times of arrival.

Looking back at the slow translational energy peak seen in the $m / e=79$ data in Figure 7 , we see that it is fit by the two $P\left(E_{\mathrm{T}}\right)$ 's in Figure 8, which extend from 0 to $23.5 \mathrm{kcal} / \mathrm{mol}$ (shown in dotted line and dot-dashed line). (We explain shortly why we separate the low translational energy channel into two contributions.) There is no signal at $m / e=41$ (Figure 9) corresponding to times of arrival of a mass 41 product from this channel; mass 41 radicals that would be momentummatched to the slow bromine atoms are all produced with enough internal energy to undergo secondary dissociation and so are detected at the secondary product masses. There are several possible secondary channels of the 1-propenyl radical, $\mathrm{H}$-atom loss to form propyne $+\mathrm{H}$, isomerization to another $\mathrm{C}_{3} \mathrm{H}_{5}$ radical isomer (followed by $\mathrm{H}$-atom loss), $\mathrm{C}-\mathrm{C}$ bond fission resulting in acetylene + methyl radical, and possibly $\mathrm{H}_{2}$ elimination yielding $\mathrm{C}_{3} \mathrm{H}_{3}+\mathrm{H}_{2}$, that are energetically available and potentially viable. Figure 4 , introduced previously in the section presenting the results of the $\mathrm{HBr}$ elimination 


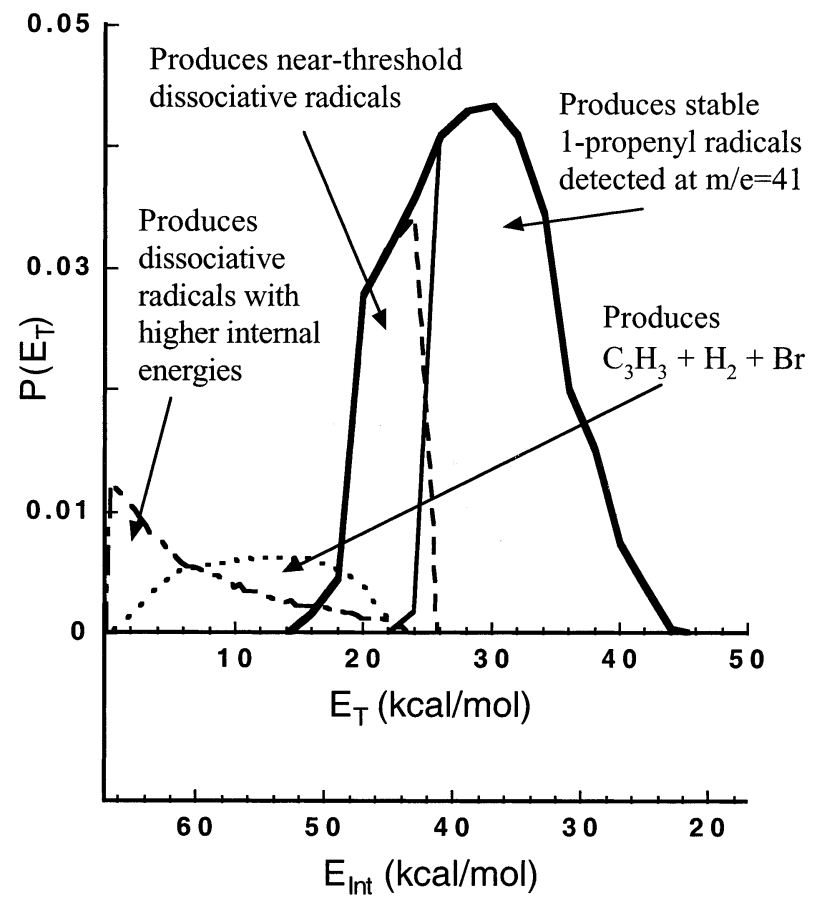

Figure 8. Photofragment recoil translational energy distributions, $P\left(E_{\mathrm{T}}\right)$ 's, obtained by forward convolution fitting of the $m / e=79 \mathrm{TOF}$ spectra. The fast $P\left(E_{\mathrm{T}}\right)$ has been decomposed into two parts, the $\mathrm{Br}$ atoms that are momentum-matched to stable 1-propenyl radicals (thin solid line), which give signal at $m / e=41$ (see Figure 9), and $\mathrm{Br}$ atoms that are momentum-matched to near-threshold, unstable 1-propenyl radicals (dashed line). The energy at which the division between the two parts of the fast $P\left(E_{\mathrm{T}}\right)$ occurs is the energy at which the fast $P\left(E_{\mathrm{T}}\right)$ needed to be truncated to fit the $m / e=41$ data. The two slow $P\left(E_{\mathrm{T}}\right)$ 's describe two different processes of cis-1-bromopropene excited with $193 \mathrm{~nm}$ light, both of which give slow $\mathrm{Br}$ atoms. The dot - dashed line $P\left(E_{\mathrm{T}}\right)$ is the translational energy distribution that describes a $\mathrm{C}-\mathrm{Br}$ bond fission channel, which produces slow $\mathrm{Br}$ atoms and unstable 1-propenyl radicals that undergo $\mathrm{C}-\mathrm{H}$ bond fission (either directly or after isomerization to the allyl radical). The dotted line $P\left(E_{\mathrm{T}}\right)$ is an $\mathrm{H}_{2}$ elimination channel. We have constructed this dotted line $P\left(E_{\mathrm{T}}\right)$ assuming that the $\mathrm{H}_{2}$ elimination is a primary process of the parent molecule excited with $193 \mathrm{~nm}$ light, followed by fast $\mathrm{C}-\mathrm{Br}$ bond fission of the $\mathrm{C}_{3} \mathrm{H}_{3} \mathrm{Br}$ coproduct that partitions the kinetic energy to the $\mathrm{Br}$ product. However, we could construct the dotted line $P\left(E_{\mathrm{T}}\right)$ by assuming the $\mathrm{H}_{2}$ elimination occurs from nascent hot 1-propenyl radicals formed in an initial $\mathrm{C}-\mathrm{Br}$ bond dissociation event, and the fit to the data does not significantly change.

reaction, shows the TOF spectra taken at m/e $=40\left(\mathrm{C}_{3} \mathrm{H}_{4}{ }^{+}\right)$ using photoionization energies of 10.0 and $10.8 \mathrm{eV}$. (The reason for presenting the two ionization energies will be explained later.) There are two peaks evident. The fast signal was easily fit by using the solid line portion of the high translational energy $P\left(E_{\mathrm{T}}\right)$ in Figure 8, indicating that this signal results from daughter ion cracking of the neutral, stable (to secondary dissociation) mass 41 radicals. Using photoionization energy rather than electron bombardment largely eliminates daughter ion cracking, yet $\mathrm{C}_{3} \mathrm{H}_{5}$ radicals have been shown ${ }^{2}$ to crack under even these soft ionization conditions. And indeed, this fast peak in the $m / e=40$ spectra is fit well with the $P\left(E_{\mathrm{T}}\right)$ used to fit the stable 1-propenyl radicals in $m / e=41$. In addition, the contribution of the fast peak at $m / e=40$ decreases with increasing ionization energy, indicating that as ionization energy is increased cracking to $m / e=39$ increases, as would be expected. To fit the slow signal and so to assess whether the 1-propenyl radical from the low kinetic energy $\mathrm{C}-\mathrm{Br}$ bond fission channel unimolecularly dissociates by $\mathrm{C}-\mathrm{H}$ fission, we first tried using a slow mass $79 P\left(E_{\mathrm{T}}\right)$ that fit the total slow $\mathrm{Br}$

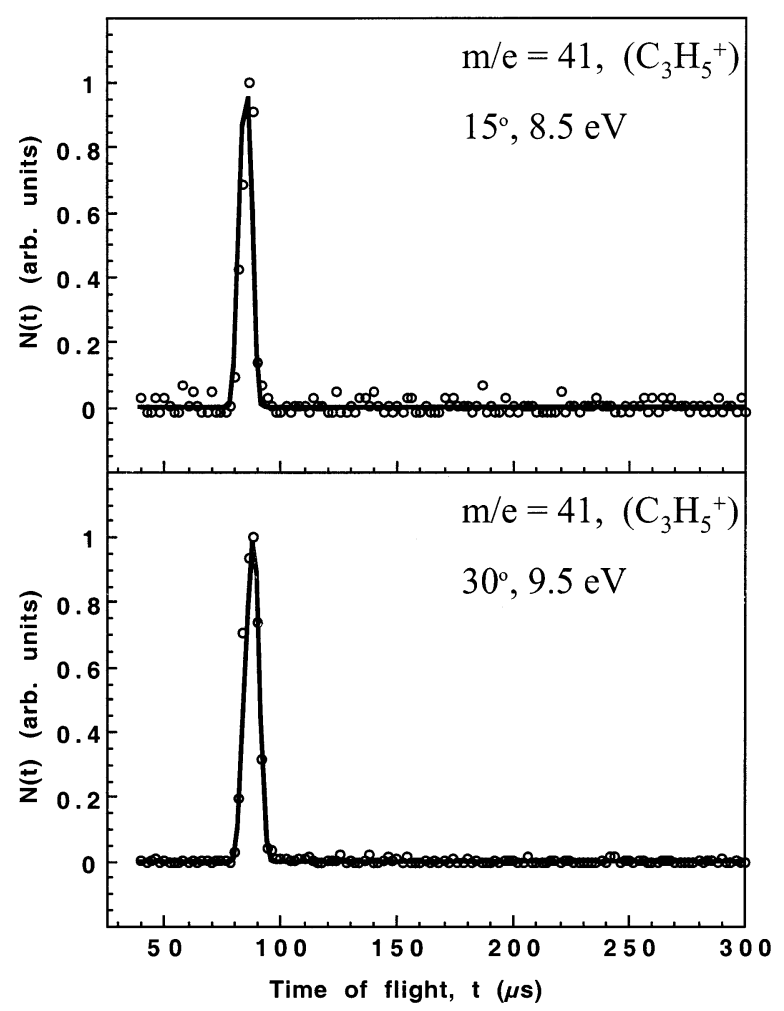

Figure 9. Time-of-flight spectra of $m / e=41\left(\mathrm{C}_{3} \mathrm{H}_{5}{ }^{+}\right)$taken for 100000 laser shots at source-detector angles of $15^{\circ}$ and $30^{\circ}$. Data are shown in open circles. The single peak is fit with the solid line portion of the fast $P\left(E_{\mathrm{T}}\right)$ shown in Figure 8 . The truncation of the $P\left(E_{\mathrm{T}}\right)$ at $\sim 25 \mathrm{kcal} /$ mol has error bars of $\pm 1 \mathrm{kcal} / \mathrm{mol}$ determined by varying the truncation point and then examining the fit to the data. This energy cutoff for 1-propenyl radicals to remain stable to secondary dissociation is consistent with the barrier height to $\mathrm{C}-\mathrm{C}$ bond fission calculated by Davis et al. should the $\mathrm{Br}$ atom formed be in the excited spin-orbit state $\left({ }^{2} \mathrm{P}_{1 / 2}\right)$.

atom signal (the sum of the two low translational energy $P\left(E_{\mathrm{T}}\right)$ 's shown in Figure 8) to fit the slower signal at $m / e=40$. This, however, unquestionably overfit the $m / e=40$ signal. If all of the slow bromine atoms fit by the total slow $P\left(E_{\mathrm{T}}\right)$ needed to fit the data at $m / e=79$ were produced by $\mathrm{C}-\mathrm{Br}$ bond fission of the cis-1-bromopropene, then some of the 1-propenyl radicals formed from $\mathrm{C}-\mathrm{Br}$ bond fission dissociate by a different pathway than $\mathrm{C}-\mathrm{H}$ fission. Because it is possible that the slow signal at $m / e=79$ arises from more than one channel that overlap to give a total slow mass $79 P\left(E_{\mathrm{T}}\right)$, only one of which produces mass 40 products, we fit the $m / e=40$ signal with the dot-dashed line $P\left(E_{\mathrm{T}}\right)$ shown in Figure 8. To do so, we hypothesized that the total slow $\mathrm{C}-\mathrm{Br}$ bond fission $P\left(E_{\mathrm{T}}\right)$ that we originally used to fit the slow data in Figure 7 must be the sum of at least two individual components, one of which fits a secondary dissociation channel of the 1-propenyl channel that gives signal at $m / e=40$ and one of which does not. Then the difference portion of the slow $P\left(E_{\mathrm{T}}\right)$ found by subtracting the portion of the $P\left(E_{\mathrm{T}}\right)$ that fit the slow signal at $m / e=40$ from the total low kinetic energy $P\left(E_{\mathrm{T}}\right)$, which fit all of the slow signal at $m / e=79$, should then fit data at another possible mass such as $m / e=39$, and indeed, the difference portion of the $P\left(E_{\mathrm{T}}\right)$, shown in dotted line in Figure 8, is required to completely fit the slow peak in the $m / e=39$ signal (see Figure 6, shown previously in the section on $\mathrm{HBr}$ elimination from cis-1bromopropene). This channel must arise from a different reaction pathway that produced low kinetic energy bromine atoms. We will present our full analysis of this reaction channel later in this section, but we note here that the dotted-line $P\left(E_{\mathrm{T}}\right)$ shown 
for this reaction in Figure 8 and used to fit the data in Figure 7 was constructed by momentum-matching mass 79 to mass 39; we believe that $\mathrm{H}_{2}$ elimination occurs from the parent cis1-bromopropene molecule. The nascent $\mathrm{C}_{3} \mathrm{H}_{3} \mathrm{Br}$ formed in the elimination reaction then undergoes $\mathrm{C}-\mathrm{Br}$ bond fission to yield $\mathrm{C}_{3} \mathrm{H}_{3}+\mathrm{Br}$ with little energy imparted to product translation.

Returning to the $m / e=40$ spectra, we now outline how the data shows that the lowest-energy dissociation channel of 1-propenyl radical is a $\mathrm{C}-\mathrm{C}$ fission pathway. First, we needed to verify that the daughter ion cracking of the $m / e=41$ radicals was the source of the fast signal at $m / e=40$; the signal at these arrival times of the $m / e=40$ products could arise from other possible sources such as mass 40 products produced from the unstable fast 1-propenyl radicals. Thus, we tried unsuccessfully to include the dashed line portion of the fast $P\left(E_{\mathrm{T}}\right)$ in Figure 8 when fitting the $m / e=40$ spectra. While the signal-to-noise and the overlap of different product channels, including a possible (though small, as already explained) contribution from $\mathrm{HBr}$ elimination from cis-1-bromopropene, which yields a cofragment of mass 40 , make it impossible to identify exact branching ratios, any contribution to the $m / e=40$ spectra from the dashed-line portion of the fast $P\left(E_{\mathrm{T}}\right)$ would need to be quite small. With this, we established that production of mass 40 secondary products could not turn on at the threshold energy for secondary dissociation (the energy where the 1-propenyl radicals first become unstable). Therefore, this enabled us, at the same time, to ascertain that the secondary decomposition by $\mathrm{C}-\mathrm{C}$ bond fission, with a calculated ${ }^{6}$ barrier lower by a few $\mathrm{kcal} / \mathrm{mol}$ than the isomerization and $\mathrm{H}$-atom loss barriers, turns on first for the hot 1-propenyl radicals formed in the $193 \mathrm{~nm}$ photodissociation of cis-1-bromopropene.

Thus there are at least two primary $\mathrm{C}-\mathrm{Br}$ bond fission channels of cis-1-bromopropene excited with $193 \mathrm{~nm}$ light that give signal at $m / e=79$ : one that produces fast $\mathrm{Br}$ atoms and mostly stable 1-propenyl radical with secondary dissociation of the 1-propenyl turning on at translational energies less than $\sim 25 \mathrm{kcal} / \mathrm{mol}$ and one in which low kinetic energy is imparted to the photofragments and all of the 1-propenyl radicals formed undergo secondary reactions such that no signal is seen at $m / e$ $=41$ from these radicals. (In addition, there is a third reaction channel that produces slow bromine atoms and mass 39 products, which may be a primary $\mathrm{C}-\mathrm{Br}$ bond fission channel, but as will be explained later, we believe these slow $\mathrm{Br}$ atoms to actually be the products of a secondary $\mathrm{C}-\mathrm{Br}$ bond fission reaction.) The truncation seen in the fast $P\left(E_{\mathrm{T}}\right)$ occurs right at the internal energy necessary to break the $\mathrm{C}-\mathrm{C}$ bond in the 1-propenyl radical, and examining the spectra at $\mathrm{m} / \mathrm{e}=26$ $\left(\mathrm{C}_{2} \mathrm{H}_{2}{ }^{+}\right)$and $m / e=15\left(\mathrm{CH}_{3}{ }^{+}\right)$, shown in Figure 10 , we see that there is in fact signal at times of arrival corresponding to $\mathrm{C}-\mathrm{C}$ bond fission of the 1-propenyl. As explained above, the comparison of the $m / e=40$ and $m / e=79$ TOF spectra shows that the $\mathrm{C}-\mathrm{C}$ fission products come from radicals with nearthreshold energy formed in the fast primary channel of cis-1bromopropene. Fitting the $\mathrm{C}-\mathrm{C}$ dissociation pathway of the 1-propenyl radical involves forward convolution fitting of the primary dissociation event, which produced the unstable but near-threshold 1-propenyl radicals that underwent dissociation to give mass 26 and 15 (indicated by the dashed line part of the fast $P\left(E_{\mathrm{T}}\right)$ shown in Figure 8) followed by fitting a recoil kinetic energy distribution involved in the secondary $\mathrm{C}-\mathrm{C}$ fission of these unstable radicals. ${ }^{19}$ Energy conservation dictates that the secondary dissociation has a total available energy range for the secondary product recoil that spans $0-24 \mathrm{kcal} / \mathrm{mol}$ and depends on the kinetic energy imparted in the primary product

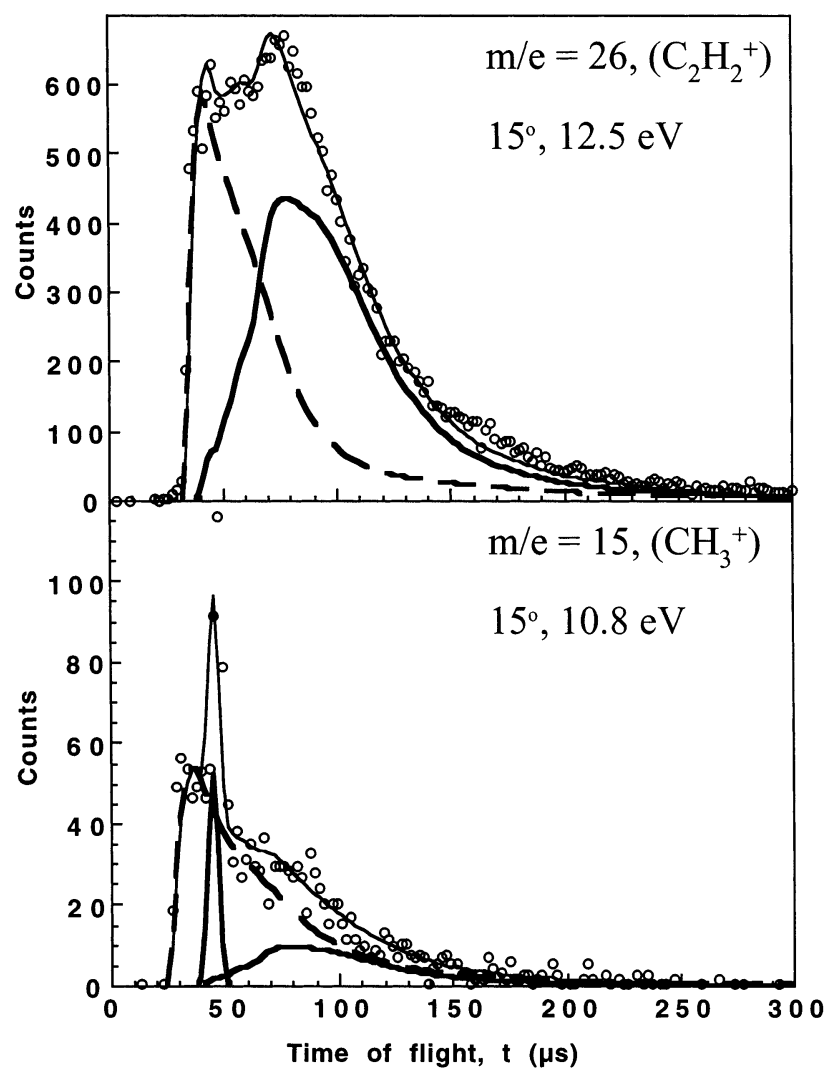

Figure 10. Time-of-flight spectra of $m / e=26\left(\mathrm{C}_{2} \mathrm{H}_{2}{ }^{+}\right)$, top, and $m / e$ $=15\left(\mathrm{CH}_{3}{ }^{+}\right)$, bottom, taken for 30000 laser shots at a source-detector angle of $15^{\circ}$. The only secondary process used to fit these data is secondary dissociation of the portion of the fast $\mathrm{C}-\mathrm{Br}$ bond fission channel that gave dissociative $m / e=41$ radicals (the dashed line portion of the fast $P\left(E_{\mathrm{T}}\right)$ in Figure 8). All other signal was fit by assuming that it arises from daughter ions of hot $m / e=41$ and $m / e=40$ radicals cracking under ionization. The long-dashed line in both spectra is the secondary process, the thicker solid line outlining a broad slow distribution is daughter ion cracking from hot $\mathrm{C}_{3} \mathrm{H}_{4}$ products from primary $\mathrm{HBr}$ elimination, and in the $m / e=15$ spectrum the additional contribution to the fit appearing as a sharp small peak shown in solid line is attributed to daughter ion cracking from hot stable mass 41 radicals so is calculated from the $P\left(E_{\mathrm{T}}\right)$ that fit the $m / e=41$ spectrum.

recoil in $\mathrm{C}-\mathrm{C}$ fission of the nascent 1-propenyl radical. Note that the fit to the signal described by this distribution is relatively insensitive to the shape of the distribution and thus the secondary $\mathrm{C}-\mathrm{C}$ bond fission $P\left(E_{\mathrm{T}}\right)$ is not well-determined by this process. The $P\left(E_{\mathrm{T}}\right)$ input for this secondary dissociation event is shown in Figure 11. This $P\left(E_{\mathrm{T}}\right)$ fit the fast edge of the $m / e=26$ (and $m / e=15$ spectra) quite well. To fit the portion of the slower signal that remained, we assumed that the $\mathrm{C}_{3} \mathrm{H}_{3}$ produced from the dissociation of the nascent hot $\mathrm{C}_{3} \mathrm{H}_{4}$ formed in the $\mathrm{HBr}$ elimination reaction of cis-1-bromopropene would have enough internal energy to undergo cracking at this higher photoionization energy to $\mathrm{C}_{2} \mathrm{H}_{2}{ }^{+}$. Propargyl radical has a literature ionization onset of $8.67 \mathrm{eV}$, so $12.5 \mathrm{eV}$ is expected to exceed the appearance energy of $\mathrm{C}_{2} \mathrm{H}_{2}{ }^{+}$from propargyl. Indeed, using the $\operatorname{HBr} P\left(E_{\mathrm{T}}\right)$ fit the remaining signal at $m / e=26$ quite well. It did slightly overfit the fast side of the slower signal, but allowing the amount of cracking to decrease as the amount of translational energy partitioned in the primary $\mathrm{HBr}$ elimination increases (thus leaving less energy for internal energy of the product that cracks to this mass) allowed us to obtain the good fit to the spectrum shown in Figure 10. Another possibility is that some surviving hot $\mathrm{C}_{3} \mathrm{H}_{4}$ produced in the primary $\mathrm{HBr}$ elimination cracked in the ionizer to give mass 26 and 15; appearance energies of mass 26 and 15 from propyne are only $\sim 15 \mathrm{eV}$. The data would be 


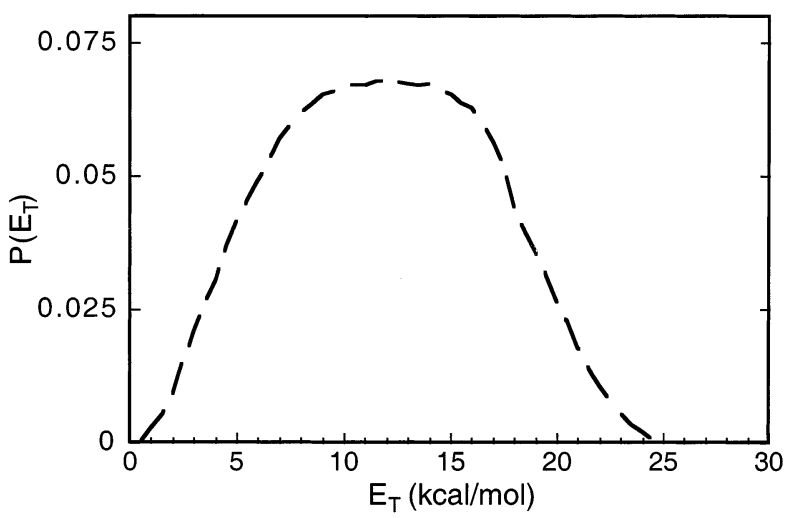

Figure 11. The secondary recoil translational energy distribution, the $P\left(E_{\mathrm{T}}\right)$, obtained by forward convolution fitting of the $m / e=26 \mathrm{TOF}$ spectra. Fitting this dissociation pathway of the 1-propenyl radical involves forward convolution fitting of the primary dissociation event, which produced the unstable but near-threshold 1-propenyl radicals (indicated by the dashed line part of the fast $P\left(E_{\mathrm{T}}\right)$ shown in Figure 8) followed by fitting a recoil kinetic energy distribution involved in the secondary $\mathrm{C}-\mathrm{C}$ fission of these unstable radicals. Energy conservation dictates that the secondary dissociation has a total available energy range for the secondary product recoil that spans $0-24 \mathrm{kcal} / \mathrm{mol}$ and depends on the kinetic energy imparted in the primary product recoil in $\mathrm{C}-\mathrm{C}$ fission of the nascent 1-propenyl radical. Note that the fit to the signal described by this distribution is relatively insensitive and thus this secondary $\mathrm{C}-\mathrm{C}$ bond fission $P\left(E_{\mathrm{T}}\right)$ is not well-determined by this process.

fit in the same manner with this assumption. An attempt to use the slow $\operatorname{Br} P\left(E_{\mathrm{T}}\right)$ that gave dissociative mass 41 momentummatched products, which gave signal at $m / e=40$ (the dotdashed $P\left(E_{\mathrm{T}}\right)$ in Figure 8$)$, to try to fit the slow signal at this mass-to-charge ratio (and at $m / e=15$ ) was unsuccessful. This shows that the contribution to this mass from daughter ions of these products is small.

The spectrum of the mass 15 product, the momentummatched partner to the mass 26, was fit similarly. However, it also shows a sharp peak at the expected time of arrival of daughter ions of mass 41 products produced in the channel that imparts high translational energy to the photofragments; this $m / e=15$ spectrum is thus fit with a total of three distributions. The fast signal, fit in dashed line, is the mass 15 cofragment from the secondary $\mathrm{C}-\mathrm{C}$ fission of the unstable 1-propenyl radical so is fit by the same two-step process as the fast signal in the $m / e=26$ spectrum, described by the dashed part of the fast $P\left(E_{\mathrm{T}}\right)$ in Figure 8. A second distribution is fit with the stable portion of the fast $P\left(E_{\mathrm{T}}\right)$ shown in Figure 8 (thin solid line) corresponding to the stable $m / e=41$ products from the fast $\mathrm{C}-\mathrm{Br}$ bond fission channel undergoing daughter ion cracking to $\mathrm{CH}_{3}{ }^{+}$in the ionizer; the third distribution is constructed from the $\operatorname{HBr} P\left(E_{\mathrm{T}}\right)$ shown in Figure 2 but modified to allow the higher translational energy portion of the full $\mathrm{HBr} P\left(E_{\mathrm{T}}\right)$ used to be gradually reduced as translational energy increases (and thus internal energy of the nascent hot $\mathrm{C}_{3} \mathrm{H}_{3} / \mathrm{C}_{3} \mathrm{H}_{4}$ products decreases, decreasing the amount of daughter ion cracking to $m / e=26$ and 15 from this channel).

We now focus on the fraction of the nascent unstable 1-propenyl radicals formed in the low kinetic energy $\mathrm{C}-\mathrm{Br}$ bond fission channel that undergo secondary $\mathrm{C}-\mathrm{H}$ bond fission (rather than $\mathrm{C}-\mathrm{C}$ bond fission) to give signal at $m / e=40$. These are identified by signal at $m / e=40$ that has the same arrival times as signal from the unstable radicals that are momentum-matched to the $\mathrm{C}-\mathrm{Br}$ bond fission $P\left(E_{\mathrm{T}}\right)$ fit by the dot-dashed line shown in Figure 8. There are two noncyclic mass 40 products energetically available from the secondary dissociation of the 1-propenyl radical, propyne $\left(\mathrm{HC} \equiv \mathrm{CCH}_{3}\right)$ and allene $\left(\mathrm{H}_{2} \mathrm{C}=\mathrm{C}=\right.$ $\mathrm{CH}_{2}$ ). To try to determine the product(s) formed from the 1-propenyl radical that give signal at $m / e=40$, we took data at both 10.0 and $10.8 \mathrm{eV}$ as well as the photoionization efficiency curve shown in Figure 5a. The literature value for the ionization onset of propyne is $10.36 \mathrm{eV}$, as compared to the literature ionization of allene of $9.69 \mathrm{eV}$. If we are making primarily propyne from the 1-propenyl radical, as would be suggested by the lower barrier height to $\mathrm{C}-\mathrm{H}$ bond fission as compared to the isomerization barrier shown in Figure 1, the leading edge of the slow peak in the spectrum photoionized at $10.0 \mathrm{eV}$, below the ionization energy onset of propyne, should be reduced from that in the spectrum taken with $10.8 \mathrm{eV}$ photoionization energy. These spectra, shown in Figure 4, are very similar, however, indicating that both allene and propyne are formed from the nascent 1-propenyl radical at internal energies at which $\mathrm{C}-\mathrm{H}$ bond fission begins to compete with $\mathrm{C}-\mathrm{C}$ fission. While the magnitude of the slow peak seems to change with respect to the fast peak, as explained previously, this is due solely to the reduction in daughter ion cracking to $m / e=40$ that occurs with increasing ionization energy (more mass 41 product cracks to $m / e=39$ instead). There is no difference in signal intensity between the two spectra at different ionization energies in the time window corresponding to the internal energy of the dissociating fragment where loss to propyne would be energetically allowed and isomerization followed by $\mathrm{H}$ atom loss to make allene would not be energetically allowed according to the barrier heights calculated by Davis et al. Examination of the PIE curve of the mass 40 product (Figure 5) shows that the curve looks very similar to that of a linear combination of cold allene and cold propyne. In Figure 5b, we show a comparison of the experimental PIE curve with PIE curves constructed using different linear combinations of cold allene and propyne; one can see that the curve formed of roughly equal amounts of allene and propyne best reproduces the experimental data. We also point out that the $m / e=40 \mathrm{TOF}$ spectra at 10.0 and $10.8 \mathrm{eV}$ are identical in shape indicating that if both allene and propyne are formed the branching ratio between $\mathrm{C}-\mathrm{H}$ bond fission from the 1-propenyl radical and isomerization to the allyl radical (followed by $\mathrm{H}$ atom loss to give allene) is only weakly dependent on the internal energy of the radical at these higher internal energies.

Now we will examine the low kinetic energy bromine $P\left(E_{\mathrm{T}}\right)$ that does not fit signal at $m / e=41$ or $m / e=40$ but only at $m / e$ $=39$. We postulate it to be a $\mathrm{H}_{2}$ elimination channel, $\mathrm{C}_{3} \mathrm{H}_{5} \mathrm{Br}$ $\rightarrow \mathrm{Br}+\mathrm{H}_{2}+\mathrm{C}_{3} \mathrm{H}_{3}$. The fits shown (Figures 6-8) are calculated for a process in which $\mathrm{H}_{2}$ elimination occurs as a primary photolysis reaction of $\mathrm{C}_{3} \mathrm{H}_{5} \mathrm{Br}$ and the nascent $\mathrm{C}_{3} \mathrm{H}_{3} \mathrm{Br}$ product all unimolecularly dissociates to $\mathrm{C}_{3} \mathrm{H}_{3}+\mathrm{Br}$ with little further release of energy to product recoil. However, we can obtain equally good fits to the data assuming the $\mathrm{H}_{2}$ elimination to result from a two-step process in which primary $\mathrm{C}-\mathrm{Br}$ bond fission results in nascent 1-propenyl radical formed with enough internal energy to overcome an expected high barrier to $\mathrm{H}_{2}$ loss. To attempt to discriminate between the two possible $\mathrm{H}_{2}$ elimination pathways, we did check for signal at $m / e=118$ $\left(\mathrm{C}_{3} \mathrm{H}_{3} \mathrm{Br}^{+}\right)$, one of the momentum-matched fragments that would result from the reaction $\mathrm{BrHC}=\mathrm{CHCH}_{3} \rightarrow \mathrm{C}_{3} \mathrm{H}_{3} \mathrm{Br}+\mathrm{H}_{2}$. We did not see any signal at this mass-to-charge ratio; however, unless a large amount of energy is partitioned into product recoil, we would not be able to see this heavy product at the sourcedetector angles sampled. Thus, we cannot determine whether the $\mathrm{Br}+\mathrm{H}_{2}+\mathrm{C}_{3} \mathrm{H}_{3}$ products are formed via primary $\mathrm{H}_{2}$ elimination prior to $\mathrm{C}-\mathrm{Br}$ bond fission or as an elimination 
from the 1-propenyl radical. We can assert, however, that the $\mathrm{C}_{3} \mathrm{H}_{3}$ molecules observed at $m / e=39$ fit as the dotted curve came from an $\mathrm{H}_{2}$ elimination process, not as two sequential $\mathrm{H}$ atom losses by $\mathrm{C}-\mathrm{H}$ bond fission events. $\mathrm{C}-\mathrm{Br}$ bond fission of cis-1-bromopropene plus secondary dissociation to the lowestenergy mass 40 product from $193 \mathrm{~nm}$ excitation of cis-1bromopropene requires $80.9+30.3=111.2 \mathrm{kcal} / \mathrm{mol}$ of energy, leaving only $36.7 \mathrm{kcal} / \mathrm{mol}$ to be partitioned into internal and translational degrees of freedom. Therefore, sequential loss of a second $\mathrm{H}$ atom from the $\mathrm{C}_{3} \mathrm{H}_{4}$ secondary product to give $\mathrm{C}_{3} \mathrm{H}_{3}$ $+\mathrm{H}$ is not energetically possible. We attempted to further characterize this channel using data at $m / e=2$ but were unsuccessful. To do so, one can detect $\mathrm{H}_{2}$ from the $193 \mathrm{~nm}$ photolysis of cis-1-bromopropene in a molecular beam in a Rydberg time-of-flight apparatus. Also an ab initio calculation of the transition state for $\mathrm{H}_{2}$ elimination from the 1-propenyl radical can identify whether it is too high in energy to compete effectively with bond fission channels, in which case attributing it to elimination in 1-bromopropene is correct.

\section{Discussion}

Unimolecular Dissociation Channels of Nascent 1-Propenyl Radicals. The most important results from these studies are the first good experimental data on the unimolecular dissociation channels of the 1-propenyl radical. There are three firm conclusions: (1) the lowest-energy dissociation barrier of the 1-propenyl radical is experimentally determined for the first time and is in agreement with the lowest-energy barrier calculated at the G3 B3LYP level of theory by Davis et al.; (2) the lowest-energy dissociation channel of the 1-propenyl radical is $\mathrm{C}-\mathrm{C}$ bond fission; (3) at higher internal energies at which $\mathrm{C}-\mathrm{H}$ bond fission begins to compete effectively with $\mathrm{C}-\mathrm{C}$ fission, the isomerization pathway to allyl radical is also opened, so the experiment detects a combination of propyne and allene secondary products.

When comparing our data to the theoretically calculated lowest-energy dissociation barrier, it is important to be explicit as to which are our experimental determinations and which are derived quantities. Our work shows clearly that the $193 \mathrm{~nm}$ photolysis of 1-bromopropene produces stable 1-propenyl radical when the kinetic energy release in the $\mathrm{C}-\mathrm{Br}$ bond fission is $>26 \mathrm{kcal} / \mathrm{mol}$ and produces 1-propenyl radical unstable to $\mathrm{C}-\mathrm{C}$ bond fission when the kinetic energy release is $<24 \mathrm{kcal} / \mathrm{mol}$. A more precise derivation of a lowest-energy barrier from these experimental observations is dependent on a good $\mathrm{C}-\mathrm{Br}$ bond energy of cis-1-bromopropene; here, we had to rely on an estimated value for the $\Delta H_{\mathrm{f}}$ of 1-propenyl. The values used, all enthalpies at $298 \mathrm{~K}$, were as follows: we used the reaction pathway of cis-1-bromopropene $\rightarrow$ allyl $+\mathrm{Br}$ atom $\rightarrow$ 1-propenyl $+\mathrm{Br}$ atom, such that

$$
\begin{aligned}
& D_{\mathrm{o}}(\mathrm{C}-\mathrm{Br})=\Delta H_{\mathrm{f}}(\text { allyl })^{14}+(\text { difference in zeroth } \\
& \text { energy level heights between allyl radical and 1-propenyl } \\
& \text { radical })^{6}+\Delta H_{\mathrm{f}}(\mathrm{Br})^{15}-\Delta H_{\mathrm{f}}(Z \text {-1-bromopropene })^{15} \\
& =40.9 \pm 0.7+23.0+26.738 \pm 0.029-9.7 \pm \\
& 1.0 \mathrm{kcal} / \mathrm{mol}
\end{aligned}
$$$$
=80.9 \pm 1.2 \mathrm{kcal} / \mathrm{mol} \text {. }
$$

This bond energy is very close to the bond energy that would be derived from the literature $\Delta H_{\mathrm{f}}(1$-propenyl $),{ }^{20}$ but we used the path above instead because that same paper has a substantial error in the heat of formation of the 2-propenyl radical.
Using this estimated bond energy to derive the energy of the lowest dissociation barrier from our data gives

$$
\begin{aligned}
E_{\text {barrier to } \mathrm{C}-\mathrm{C} \text { fission }}= & h v-D_{\mathrm{o}}- \\
\left(E_{\mathrm{T}}\right. & \text { cutoff for stable 1-propenyl) }-\Delta E_{\mathrm{Br} * \leftarrow \mathrm{Br}} \\
= & 147.9-80.9-\sim 25-10.54 \mathrm{kcal} / \mathrm{mol} \\
= & 31.5 \pm 2 \mathrm{kcal} / \mathrm{mol} \\
& \text { (including our experimental uncertainty). }
\end{aligned}
$$

When the heats of formation of the relevant species are available at $0 \mathrm{~K}$, one should insert those in the above calculation to arrive at a more accurate determination and use $24 \mathrm{kcal} / \mathrm{mol}$ as the $E_{\mathrm{T}}$ cutoff because that is more appropriate for the parent molecules with less than average internal energy (the mean internal energy of the parent molecules is about $2 \mathrm{kcal} / \mathrm{mol}$ at this nozzle temperature).

As stated above, the lowest-energy dissociation channel of the 1-propenyl radical is a $\mathrm{C}-\mathrm{C}$ bond fission channel producing acetylene and methyl products. The fast velocities of these unimolecular dissociation products would be unexpected if we did not take into account the rotational kick imparted by the $\mathrm{C}-\mathrm{Br}$ bond fission process. Loss of a bromine atom from cis1-bromopropene imparts considerable angular momentum to the 1-propenyl radical, and as seen in the photodissociation study of allyl iodide, ${ }^{18}$ the centrifugal force raises the barrier for $\mathrm{C}-\mathrm{H}$ bond fission. Because total angular momentum must be conserved, any angular momentum not appearing in rotation of the products must appear in the orbital angular momentum of the scattered fragments, $L=\mu v_{\text {rel }} b$ where $\mu$ is the reduced mass, $v_{\text {rel }}$ is the center-of-mass velocity, and $b$ is the impact parameter. However, $\mathrm{C}-\mathrm{C}$ fission of the 1-propenyl radical involves a much larger $\mu$ and a larger $b$ than $\mathrm{C}-\mathrm{H}$ fission at the central carbon, so an increase in $v_{\text {rel }}$ can allow $L=\mu v_{\text {rel }} b$ to account for much of the angular momentum without requiring the products to be highly rotationally excited. This explanation may account for why the secondary mass 26 and mass 15 products produced by the $\mathrm{C}-\mathrm{C}$ bond fission process have larger velocities than we would otherwise expect. It also suggests that the branching to the $\mathrm{C}-\mathrm{C}$ fission channel at energies at which the $\mathrm{C}-\mathrm{H}$ bond fission channel is energetically allowed may be even more dominant than the relative barrier energies might suggest (because $\mathrm{C}-\mathrm{H}$ fission has a more substantial additional centrifugal barrier).

Finally, we observed that at higher internal energies, at which $\mathrm{C}-\mathrm{H}$ bond fission begins to compete effectively with $\mathrm{C}-\mathrm{C}$ fission, both propyne and allene secondary products are observed. Whereas propyne products may result from $\mathrm{C}-\mathrm{H}$ bond fission in 1-propenyl radical, allene products must result from a two-step process, the most simple of which is isomerization to allyl followed by $\mathrm{C}-\mathrm{H}$ bond fission to form allene $+\mathrm{H}$. However, significant branching to such an allene $+\mathrm{H}$ channel is inconsistent with the relative heights of the 1-propenyl to $\mathrm{H}+$ propyne barrier versus the 1-propenyl to allyl isomerization barrier calculated by Davis et al. as 58.8 and $64.0 \mathrm{kcal} /$ mol, respectively. Any additional centrifugal barrier to $\mathrm{C}-\mathrm{H}$ fission cannot explain why isomerization (followed by $\mathrm{H}$ atom loss to form allene) effectively competes with direct $\mathrm{C}-\mathrm{H}$ bond fission of the 1-propenyl radical to form propyne because the isomerization barrier must also be centrifugally corrected. Thus, our data indicate that the relative energies of the calculated barrier for 1-propenyl $\rightarrow \mathrm{H}+$ propyne and the barrier for isomerization of 1-propenyl $\rightarrow$ allyl are likely in error.

Primary Channels of cis-1-Bromopropene Excited with 193 nm Light. Comparing the results of this study of cis-1- 
bromopropene photolyzed at $193 \mathrm{~nm}$ with those performed on vinyl bromide shows that there are interesting similarities and differences. Wodtke et al. studied the $193 \mathrm{~nm}$ photodissociation of vinyl bromide ${ }^{8}$ and saw a competition between two processes, $\mathrm{C}-\mathrm{Br}$ bond fission and $\mathrm{HBr}$ elimination. In vinyl bromide, one $\mathrm{C}-\mathrm{Br}$ bond fission pathway, a reaction that partitioned a large amount of translational energy to product recoil, was observed. In contrast, two $\mathrm{C}-\mathrm{Br}$ bond fission processes were observed in this study on cis-1-bromopropene. One of these $\mathrm{C}-\mathrm{Br}$ bond fission processes releases a large amount of translational energy to the photofragments, as was seen with vinyl bromide, and we thus assign it (as they did) to an excited-state dissociation pathway. The peak of the translational energy distribution used to fit this fast $\mathrm{C}-\mathrm{Br}$ bond fission process in cis-1-bromopropene is $\sim 30 \mathrm{kcal} / \mathrm{mol}$; the $P\left(E_{\mathrm{T}}\right)$ used by Wodtke et al. peaked at slightly higher energy, $\sim 40 \mathrm{kcal} / \mathrm{mol}$. Another difference between the two studies is that Wodtke et al. give evidence that the high kinetic energy channel produces both $\mathrm{Br} *\left({ }^{2} \mathrm{P}_{1 / 2}\right)$ and $\mathrm{Br}\left({ }^{2} \mathrm{P}_{3 / 2}\right)$ atoms. In variance with the vinyl bromide work, we see only the production of $\operatorname{Br}\left({ }^{2} \mathrm{P}_{1 / 2}\right)$, because our spectra at $m / e=79$ taken at the two ionization energies (see Figure 7) demonstrate no observable difference between the spectrum ionized with energy less than that needed for ground-state $\mathrm{Br}$ atom to lose an electron, the $11.5 \mathrm{eV}$ spectrum, and the spectrum ionized with higher energy, $15.5 \mathrm{eV}$. (Wodtke et al.'s evidence for branching to ground-state $\mathrm{Br}$ atoms was that the $P\left(E_{\mathrm{T}}\right)$ used to fit the momentum-matched fragment from $\mathrm{C}-\mathrm{Br}$ bond fission in vinyl bromide, the vinyl radical, begins to show a reduction near $40 \mathrm{kcal} / \mathrm{mol}$ in product translation due to secondary dissociation to $\mathrm{C}_{2} \mathrm{H}_{2}+\mathrm{H}$. If vinyl radicals were formed with these kinetic energies with an excited $\left({ }^{2} \mathrm{P}_{1 / 2}\right) \mathrm{Br}$ cofragment, they would be energetically stable.)

A second $\mathrm{C}-\mathrm{Br}$ bond fission pathway in cis-1-bromopropene, not seen in the work on vinyl bromide, produced low kinetic energy $\mathrm{Br}$ atoms and unstable 1-propenyl radicals. Because the $P\left(E_{\mathrm{T}}\right)$ that describes this process peaks near $0 \mathrm{kcal} / \mathrm{mol}$, we assign this channel as $\mathrm{C}-\mathrm{Br}$ bond fission that occurs on the ground state of cis-1-bromopropene following internal conversion from the excited-state surface accessed in the initial excitation.

$\mathrm{HBr}$ elimination was also seen in the study on vinyl bromide by Wodtke et al. They observed a branching ratio of 1.28:1 for formation of $\mathrm{Br} / \mathrm{HBr}$. The theoretical studies of Mains et al., who investigated the dissociation dynamics of vinyl bromide at $193 \mathrm{~nm}$ by using classical trajectory methods on adiabatic excited-state potentials, indicated that for excited state dissociation no $\mathrm{HBr}$ was formed but only $\mathrm{C}-\mathrm{Br}$ bond fission occurred. ${ }^{11}$ Abrash et al. ${ }^{9}$ studied the thermal gas-phase decomposition of vinyl bromide on the ground-state surface and did observe $\mathrm{HBr}$ elimination. In that study, as the excitation energy was increased to $6.4 \mathrm{eV}$, the branching ratio between the different possible reaction pathways of vinyl bromide changed from all $\mathrm{HBr}$ elimination at low energies to $48 \% \mathrm{H}_{2}$ elimination and $44.5 \%$ $\mathrm{HBr}$ elimination (both elimination mechanisms were thought to be primarily three-centered reactions) along with a small amount of $\mathrm{C}-\mathrm{Br}$ and $\mathrm{C}-\mathrm{H}$ bond fission. Mains et al. suggested that the $\mathrm{HBr}$ elimination seen by Wodtke et al. in vinyl bromide occurred after internal conversion to the ground state, and indeed, this mechanism was suggested in the paper by Wodtke et al. However, the large anisotropy for the $\mathrm{HBr}$ elimination channel of $\beta=0.70 \pm 0.02$ observed by Wodtke is in apparent contradiction to this inferred internal conversion mechanism. Finally, Wodtke et al. did not report seeing any $\mathrm{H}_{2}$ elimination from vinyl bromide excited with $193 \mathrm{~nm}$ light, while the matrix results of Abrash et al. showed that both $\mathrm{HBr}$ elimination and $\mathrm{H}_{2}$ elimination occurred. It may be that our $\mathrm{C}_{3} \mathrm{H}_{3}+\mathrm{H}_{2}+\mathrm{Br}$ channel is the analogue of that $\mathrm{H}_{2}$ elimination pathway, with the $\mathrm{H}_{2}$ elimination followed by unimolecular dissociation of the hot $\mathrm{C}_{3} \mathrm{H}_{3} \mathrm{Br}$ fragments.

We have not found in the literature any potential energy surfaces calculated for cis-1-bromopropene, but the BornOppenheimer potential energy surfaces in the singlet and triplet manifolds (neglecting spin-orbit coupling) for $\mathrm{C}-\mathrm{Br}$ bond fission in vinyl bromide were calculated by Michl et al. ${ }^{13}$ and studied and expanded upon by Mains et al., ${ }^{11}$ who postulated that excitation of vinyl bromide with $6.4 \mathrm{eV}$ accessed a combination of repulsive potentials. They suggested that possibly three or four different surfaces could be important in the transition. Their trajectory calculations also seemed to demonstrate the multiple nature of the surface accessed with $193 \mathrm{~nm}$ light: with the assumption of electronic adiabaticity in their calculations, the authors found the calculated kinetic energy distribution far too narrow unless a linear combination of distributions computed by using at least three of the repulsive excited-state potentials was used. However, we note here that the electronic transition in cis-1-bromopropene with $193 \mathrm{~nm}$ light likely has significant $\pi^{* \leftarrow \pi}$ character as in the other haloalkenes, whereas the surfaces calculated by Michl et al. do not include an energetically accessible $\pi^{* \leftarrow} \pi$ transition in the singlet manifold. It is likely that to obtain a satisfactory theoretical understanding of the system both strong spin-orbit coupling and electronically nonadiabatic effects must be included.

We now briefly compare our results with the results of Zhu et al., the authors of the previous work on the $193 \mathrm{~nm}$ photodissociation of bromopropene in a crossed laser-molecular beam apparatus. Our findings are quite different from theirs. The work of Zhu et al. detected only one broad distribution for $\mathrm{C}-\mathrm{Br}$ bond fission (we conclude that the slow channel that we obtain here was obscured in that work by a major contribution of clusters). That fast kinetic energy distribution seen by Zhu et al. peaked near $20 \mathrm{kcal} / \mathrm{mol}$ and included a high-energy tail that extends past $60 \mathrm{kcal} / \mathrm{mol}$. (Our data does not include significant energy partitioning to product recoil beyond $\sim 40$ $\mathrm{kcal} / \mathrm{mol}$.) They did not report seeing any $\mathrm{HBr}$ elimination. However, the authors only took their data at mass 81 and did not attempt to detect any momentum-matched cofragments. The authors postulated that nascent 1-propenyl radicals were not formed, concluding that an isomerization of 1-propenyl radical to allyl occurs either before or simultaneously with the $\mathrm{C}-\mathrm{Br}$ bond fission process. They based this on a claim (unsupported by their data or fits) that they observed the reaction process partitioning $100 \mathrm{kcal} / \mathrm{mol}$ to product translation, whereas inspection of their $P\left(E_{\mathrm{T}}\right)$ shows their kinetic energy distribution only extending to $\sim 60 \mathrm{kcal} / \mathrm{mol}$.

Acknowledgment. This work was supported by the National Science Foundation under Grant No. CHE-0109588. The Chemical Dynamics Beamline is supported by the Director, Office of Science, Office of Basic Energy Sciences, Chemical Sciences Division of the U.S. Department of Energy under Contract No. DE-AC03-76SF00098. The ALS facility is supported by the Director, Office of Science, Office of Basic Energy Sciences, Materials Sciences Division of the U.S. Department of Energy, under the same contract. The authors thank Jinian Shu for his assistance in taking some of the data presented and Tom Baer for his support of our work at the Chemical Dynamics Beamline, endstation 9.0.2.1, at the ALS. 


\section{References and Notes}

(1) Mueller, J. A.; Parsons, B. F.; Butler, L. J.; Qi, F.; Sorkhabi, O.; Suits, A. G. J. Chem. Phys. 2001, 114 (10), 4505.

(2) Morton, M. L.; Butler, L. J.; Stevenson, T. A.; Qi, F. J. Chem. Phys. 2002, 116 (7), 2763.

(3) Deyerl, H. J.; Gilbert, T.; Fischer, I.; Chen, P. J. Chem. Phys. 1997 107 (8), 3329. Deyerl, H. J.; Fischer, I.; Chen, P. J. Chem. Phys. 1999, 110 (3), 1450. Stranges, D.; Stemmler, M.; Yang, X.; Chesko, J. D.; Suits, A.

G.; Lee, Y. T. J. Chem. Phys. 1998, 109 (13), 5372.

(4) Mueller, J. A.; Miller, J. L.; Butler, L. J.; Qi, F.; Sorkhabi, O.; Suits, A. G. J. Phys. Chem. A 2000, 104 (48), 11261.

(5) Zhu,W.-s.; Zhao, X.-s.; Han, D.-g.; Li, R.-j.; Zhong, Q.-h.; Zhu, Q.-h. Chem. Phys. Lett. 1993, $204(5,6), 538$.

(6) Davis, S. G.; Law, C. K.; Wang, H. J. Phys. Chem. A 1999, 103 (30), 5889.

(7) Ondruschka, B.; Ziegler, U.; Zimmermann, G. Z. Phys. Chem. (Leipzig) 1986, 267 (6), 1127.

(8) Wodtke, A. M.; Hintsa, E. J.; Somorjai, J.; Lee, Y. T. Isr. J. Chem. 1989, 29, 383

(9) Abrash, S. A.; Zehner, R. W.; Mains, G. J.; Raff, L. M. J. Phys. Chem. 1995, 99 (10), 2959.

(10) Agrawal, P. M.; Sorescu, D. C.; Raff, L. M.; Abrash, S. A. J. Phys Chem. 1995, 99 (41), 14959. Coffey, D., Jr.; Smith, B. J.; Radom, L. J. Chem. Phys. 1993, 98 (5), 3952. Katayanagi, H.; Yonekuira, N.; Suzuki, T. Chem. Phys. 1998, 231 (2, 3), 345. Kay, R. D.; Raff, L. M. J. Phys. Chem. A 1997, 101 (6), 1007. Laws, P. A.; Hayley, B. D.; Anthony, L. M.; Roscoe, J. M. J. Phys. Chem. A 2001, 105 (10), 1830. Liu, D.-K.; Letendre,
L. T.; Dai, H.-L. J. Chem. Phys. 2001, 115 (4), 1734. Paolucci, D. M.; Gunkelman, K.; McMahon, M. T.; McHugh, J.; Abrash, S. A. J. Phys. Chem 1995, 99 (26), 10506. Rahaman, A.; Raff, L. M. J. Phys. Chem. A 2001, 105 (11), 2147. Rahaman, A.; Raff, L. M. J. Phys. Chem. A 2001, 105 (11), 2156.

(11) Mains, G. J.; Raff, L. M.; Abrash, S. A. J. Phys. Chem. 1995, 99 (11), 3532 .

(12) Schander, J.; Russell, B. R. J. Am. Chem. Soc. 1976, 98 (22), 6900

(13) Michl, J.; Bonacic-Koutecky, V. Electronic Aspects of Organic Photochemistry; John Wiley and Sons: New York, 1990.

(14) Tsang, W. In Energetics of Organic Free Radicals; Martinho Simoes, J. A., Greenberg, A., Liebman, J. F., Eds.; Blackie Academic and Professional: London, 1996; p 22.

(15) NIST Chemistry WebBook, NIST Standard Reference Database Number 69; Mallard, W. G., Linstrom, P. J., Eds.; National Institute of Standards and Technology: Gaithersburg, MD 20899, July 2001 (http:// webbook.nist.gov).

(16) Yang, X. Lin, J.; Lee, Y. T.; Blank, D. A.; Suits, A. G.; Wodtke, A. M. Rev. Sci. Instrum. 1997, 68 (9), 3317. Blank, D. Ph.D. Thesis, University of California, Berkeley, CA, 1997.

(17) Pratt, S. Private communication.

(18) Szpunar, D. E.; Morton, M. L.; Butler, L. J.; Regan, P. M. J. Phys. Chem. A, submitted for publication, 2002.

(19) CMLAB2, version 5/93, modified by J. D. Myers. This is an interactive version built on the original CMLAB2 program: Zhao, X.; Ph.D. Thesis, University of California, Berkeley, CA, 1988

(20) Zhang, X.-M. J. Org. Chem. 1998, 63 (6), 1872. 